\title{
The best leadership practices of principals in high performing and high poverty schools in Ohio
}

\author{
Mark Furda \\ West Virginia University
}

Follow this and additional works at: https://researchrepository.wvu.edu/etd

\section{Recommended Citation}

Furda, Mark, "The best leadership practices of principals in high performing and high poverty schools in Ohio" (2009). Graduate Theses, Dissertations, and Problem Reports. 2877.

https://researchrepository.wvu.edu/etd/2877

This Dissertation is protected by copyright and/or related rights. It has been brought to you by the The Research Repository @ WVU with permission from the rights-holder(s). You are free to use this Dissertation in any way that is permitted by the copyright and related rights legislation that applies to your use. For other uses you must obtain permission from the rights-holder(s) directly, unless additional rights are indicated by a Creative Commons license in the record and/ or on the work itself. This Dissertation has been accepted for inclusion in WVU Graduate Theses, Dissertations, and Problem Reports collection by an authorized administrator of The Research Repository @ WVU.

For more information, please contact researchrepository@mail.wvu.edu. 
The Best Leadership Practices of Principals in High Performing and High Poverty Schools in Ohio

\author{
Mark Furda
}

\author{
Dissertation submitted to the \\ College of Human Resources and Education \\ at West Virginia University \\ in partial fulfillment of the requirements \\ for the degree of \\ Doctor of Education \\ in
}

Educational Leadership Studies

Paul Chapman, Ph.D., Chair

Terence Ahern, Ph.D.

Ernest Goeres, Ph.D.

Richard Hartnett, Ed.D.

Charles Joyce, Ed.D.

Department of Educational Leadership Studies

Morgantown, West Virginia

2009

Keywords: Educational Leadership, Schools of Promise, High Poverty Schools, Kouzes and Posner, LPI, Student Achievement 


\begin{abstract}
The Best Leadership Practices of Principals in

High Performing and High Poverty Schools in Ohio
\end{abstract}

Mark A. Furda

The current accountability movement faced by schools throughout the country has prompted educators to close the achievement gap or else face a barrage of federal, state, and public backlash. Schools which have met overall standards will not be considered successful unless they have done something to close the achievement gap. The gaps generally occur among the economically disadvantaged students, minority groups, and those with learning disabilities. The subgroup of particular interest for this research is low socio-economic status students (SES). Principals are the instructional leaders of their buildings. This research focuses on how school leaders are helping disadvantaged students.

To determine what leaders of high performing and high poverty schools are doing to close the achievement gap, a mixed methodology study was completed. Principals in Ohio Schools of Promise (high poverty schools which achieve at high levels on the Ohio Achievement Tests) were asked to complete the Kouzes and Posner Leadership Profile Inventory (LPI) self-survey. A comparison of urban and rural principals was conducted using multiple independent samples t-tests. The results of the survey were also the basis for identifying thirty teachers to interview. The interviews were designed to identify the best practices of principals in these high performing and high poverty schools. A regression analysis was performed to examine possible links between any of several demographic variables and LPI mean scores.

Results of the statistical tests indicated no significant differences in how urban and rural principals in Schools of Promise viewed their strengths and weaknesses as leaders. The regression analysis suggested there a statistically significant relationship between the composite LPI mean scores of principals and both administrative years of experience and student teacher ratio at the .05 level. Emergent themes resulting from the teacher surveys revealed best practices in five leadership areas: modeling the way, inspiring a shared vision, challenging the process, encouraging the heart, and enabling others to act.

The achievement gap between students from low SES backgrounds and their more affluent counterparts has been closed in many schools. The results of this study demonstrate that there are specific strategies leaders can take to help close the gap. The study suggests important steps which can be taken by educators at the building and district levels, as well as the graduate level, to help all students achieve at high levels. 
Table of Contents

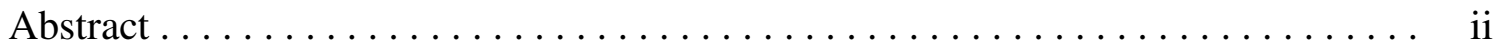

Table of Contents .............................

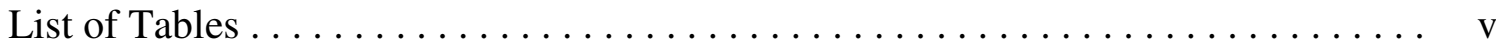

List of Figures $\ldots \ldots \ldots \ldots \ldots \ldots \ldots \ldots \ldots \ldots \ldots \ldots \ldots \ldots \ldots \ldots \ldots \ldots$

CHAPTER 1 - INTRODUCTION $\ldots \ldots \ldots \ldots \ldots \ldots \ldots \ldots \ldots \ldots \ldots \ldots \ldots$

Statement of Problem and Professional Significance ............. 1

Purpose of the Study ...................... 4

Overview of the Method $\ldots \ldots \ldots \ldots \ldots \ldots \ldots \ldots \ldots \ldots \ldots$

Researcher Bias and Delimitations . . . . . . . . . . . . 6

Significance and Purpose of the Study . . . . . . . . . . . . 7

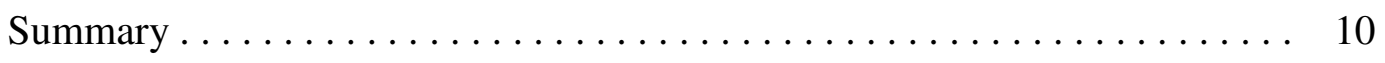

CHAPTER 2 - REVIEW OF LITERATURE $\ldots \ldots \ldots \ldots \ldots \ldots \ldots \ldots \ldots \ldots$

Leadership Theory $\ldots \ldots \ldots \ldots \ldots \ldots \ldots \ldots \ldots \ldots \ldots \ldots \ldots$

Educational Leadership . . . . . . . . . . . . . . . . . . 21

High Performing High Poverty Schools . . . . . . . . . . . . . . 33

Kouzes and Posner Leadership Practices Inventory . . . . . . . . . . . 47

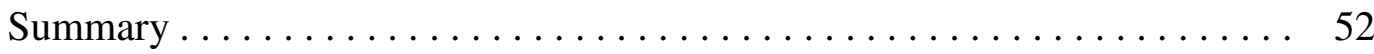

CHAPTER 3 - METHOD $\ldots \ldots \ldots \ldots \ldots \ldots \ldots \ldots \ldots \ldots \ldots \ldots \ldots$

Population and Sample $\ldots \ldots \ldots \ldots \ldots \ldots \ldots \ldots \ldots \ldots \ldots \ldots \ldots$

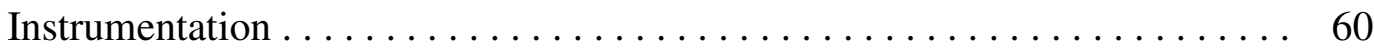

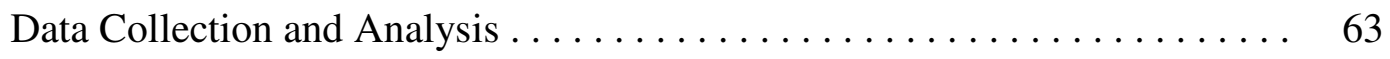

Guarantee of Anonymity and Confidentiality .............. 67 
Summary ............................... 67

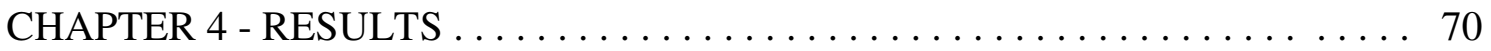

Principal and School Characteristics . . . . . . . . . . . . 70

Results Across Research Questions . . . . . . . . . . . . . . . . 75

The Researcher ............................. 81

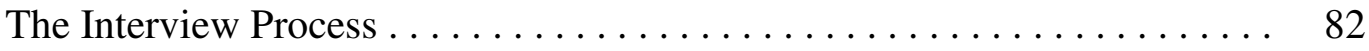

Emergent Themes of the Principals' Practices Across Leadership

Categories ........................... 82

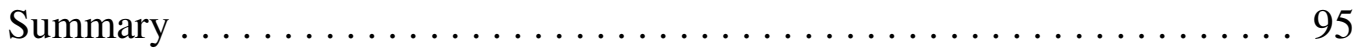

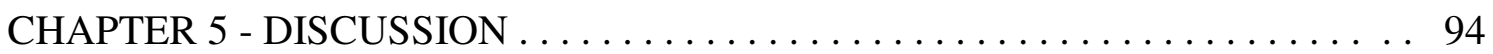

Leadership Perception and Demographic Characteristics . . . . . . . . . . 97

Research Questions ........................... 99

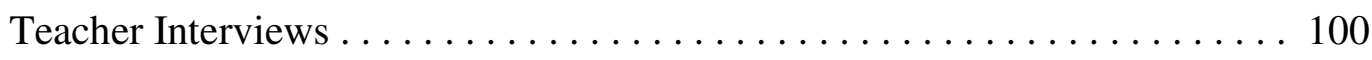

Summary of Best Practices . . . . . . . . . . . . . . . . . . 109

Implications for Further Research $\ldots \ldots \ldots \ldots \ldots \ldots \ldots \ldots \ldots \ldots$

Implications for Stakeholders . . . . . . . . . . . . . . . . . 112

Conclusion .............................. 114

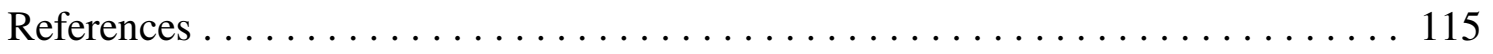

Appendix A: Schools of Promise Criteria . . . . . . . . . . . . . . 122

Appendix B: Cover Letter and Demographic Data Sheet . . . . . . . . . . . 123

Appendix C: Leadership Practices Inventory Self Survey . . . . . . . . . . . 125

Appendix D: Social and Behavioral Researcher Training . . . . . . . . . . 127

Appendix E: Kouzes and Posner Leadership Profile Inventory Permission . . . . . . 128 
List of Tables

Table 1 Proposed Sample for Study $\ldots \ldots \ldots \ldots \ldots \ldots \ldots \ldots \ldots$

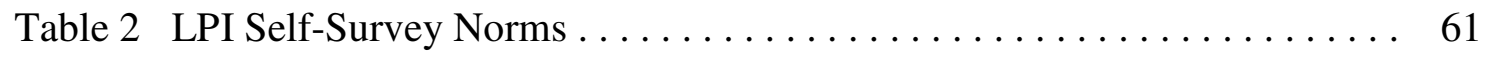

Table 3 Internal Reliability of Leadership Profile Inventory Self Form . . . . . . . 62

Table 4 Timeline for Study . . . . . . . . . . . . . . . . . . . . . 69

Table 5 Descriptive Data Means of Participating Schools and Principals . . . . . . 72

Table 6 Descriptive Statistics of Principals Self-Reported Leadership Practices and LPI . . . . . . . . . . . . . . . . 74

Table 7 Multiple Independent Samples t-tests . . . . . . . . . . . . 76

Table 8 Rank-Order of LPI Mean Scores for Urban and Rural Schools by Leadership Category . . . . . . . . . . . . . . . . . . . . 79

Table 9 Summary of Regression Analysis for Variables Predicting LPI

Mean Score . . .......................... 90 


\section{List of Figures}

Figure 1 Number of Participating Schools by Grade Configuration . . . . . . . . . 73

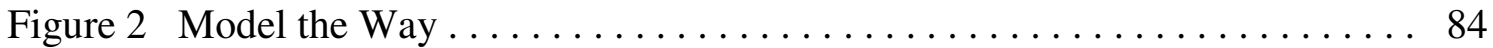

Figure 3 Inspire a Shared Vision $\ldots \ldots \ldots \ldots \ldots \ldots \ldots \ldots \ldots \ldots \ldots \ldots$

Figure 4 Challenge the Process $\ldots \ldots \ldots \ldots \ldots \ldots \ldots \ldots \ldots \ldots \ldots \ldots$

Figure 5 Enable Others to Act $\ldots \ldots \ldots \ldots \ldots \ldots \ldots \ldots \ldots \ldots \ldots \ldots \ldots \ldots$

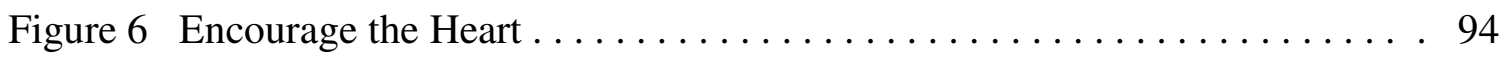




\section{CHAPTER 1}

\section{Introduction}

In this introduction, a brief discussion about the achievement gap which exists between many high poverty schools and their more affluent counterparts is presented. The rest of the chapter is divided into five sections. The first outlines the problem of the achievement gap which exists in American schools, and addresses the evidence that supports the notion of some high poverty schools achieving at high levels. It also poses a problem statement that illustrates the importance of leadership and its impact on the effectiveness of high poverty schools. The second section is an overview of the method and includes the presentation of research questions. The proceding section notes researcher bias and delimitations of the study. The fourth section explains the significance of the study. Finally, a brief summary concludes the chapter.

\section{Statement of the Problem and Professional Significance}

The current accountability movement faced by schools throughout the country has prompted educators to close the achievement gap or else face a barrage of federal, state, and public backlash. Schools which have met overall standards will not be considered successful unless they have done something to close the achievement gap. Whenever the achievement level on standardized tests differs among demographic groups, an achievement gap exists (ODE, 2006). The gaps generally occur among the economically disadvantaged students, minority groups, and those with learning disabilities. These students consistently perform lower than their white and middle class counterparts. The subgroup of particular interest for this research is low socio-economic status students 
(SES). The No Child Left Behind Act (NCLB) sets performance standards for subgroups. The National Center for Educational Statistics (2006) reports that $4^{\text {th }}$ grade math achievement scores were significantly lower for those students eligible for free and reduced lunch when compared to other groups. The United States Department of Education (USDE) considers students on free and reduced lunch as the primary indicator of low SES. The Ohio Department of Education reports that for every 10 percent increase in the poverty level of a school, achievement in reading decreases by 5.6 percent (2003). In 2005, the National Center for Education Statistics reported an existing gap in the areas of reading and math in fourth and eighth grade (2007). Nearly a 30 point gap in scores existed between white students and their black and Hispanic counterparts in reading at both the fourth and eighth grade levels. In mathematics, the eighth grade discrepancy between whites and blacks was about 35 percent, while the gap was about 27 percent between whites and Hispanics. A clear gap exists when examining SAT scores as well (NCES, 2007). White students scored considerably higher than blacks in Critical Reading (94 points) and Mathematics (107 points). The results are similar (although the discrepancy not quite as large) when comparing white students with Hispanic students. Similar results can be found when comparing students by socioeconomic status using percentage of free/reduced lunch rate as the variable. To add to the backdrop, there is a clear connection between educational attainment and wealth. The U.S. Census Bureau (2007) reports that in 2003 the average annual income of those without a high school diploma to be $\$ 16,128$. Those with a high school diploma earned an average of $\$ 25,487$, and those obtaining at least a bachelor's degree earned $\$ 49,050$ annually. The relationship is clear: educational level and financial success walk hand in hand. 
Despite the apparent correlation between poverty and low academic achievement, some economically disadvantaged schools manage to achieve at high levels. Mandated accountability has resulted in state testing programs that provide an atmosphere of high stakes single performance indicators. The testing data reveal that some high poverty schools have indeed closed the achievement gap in spite of the pressures. At the conclusion of the 2005-2006 academic year, 117 schools in Ohio were recognized as Schools of Promise by the Ohio Department of Education. Following the 2006-2007 academic year the number of schools designated as Schools of Promise rose to 194. This distinction is given to schools with at least forty percent of their students from disadvantaged backgrounds that met or surpassed the 75 percent standard in reading or mathematics on the Ohio Achievement Tests or the Ohio Graduation Test. The award is also given to schools demonstrating high achievement in racial, ethnic, or low-income subgroups when combined across grade levels from third to tenth grade (see Appendix A). Many other states present similar awards which acknowledge schools that successfully close the achievement gap despite serving areas of high poverty.

Discrepancies in achievement levels exist among several groups of students. The NCLB Act demands these gaps disappear, and that all children achieve at high levels. School and district level educators unable to affect overall student performance toward the gap face an array of consequences. Some of the consequences under NCLB include: replacing key staff, turning the operation of the school over to the state, extending the school year or school day, and offering school choice just to name a few (ODE, 2008). Educators have a responsibility to ensure all students fulfill their academic potential. The globalization of the world economy has created a job market where workers are required 
to have a generalist skill set. Employability depends now more than ever on problem solving, teamwork, critical thinking, and the ability to make oral and written presentations (Friedman, 2005; Murnane, 1996). Student failure in school is likely to turn into a life long sentence of poverty. The daunting task faced by schools is to close the achievement gap for all subgroups.

Principals are the instructional leaders of their buildings. Those in buildings distinguished by high poverty rates are held responsible for doing whatever it takes to help their students achieve at a level comparable to students in middle-class schools. If SES is the best indicator of academic success in American public schools, then every school leader is obligated to help wipe out this statistic.

There is ample evidence that principals in high poverty schools do make a difference when it comes to helping disadvantaged students perform well. Edmonds (1979) noted that strong building leadership was a common element in his study of HP/HP schools. The Effective Schools Movement which began in the 1980's yielded similar findings (Lezotte, 2008). Though the evidence exists, the details of the connection between school leadership and academic achievement remain unclear. Thus, the problem is the inability to link what type of leader it takes to be effective in low SES schools. Research focused on how school leaders are helping disadvantaged students succeed is worthy of doing.

\section{Purpose of the Study}

The purpose of this study is to examine and compare the leadership practices of urban and rural school principals that work in schools which the Ohio Department of Education has identified as high performing and high poverty. Further, this study will 
identify the best practices of these principals. To study and compare the leadership practices and behaviors of principals in Ohio Schools of Promise, the categories used will be derived from the five practices of exemplary leadership as outlined by Kouzes and Posner (2002). The instrument used will be the Leadership Profile Inventory (LPI) as designed by Kouzes and Posner. The leadership profiles will be comprised of five categories. The categories include: modeling the way, inspiring a shared vision, challenging the process, enabling others to act, and encouraging the heart.

Overview of the Method

The leadership of the principal plays an important role in school effectiveness. The Center for Educational Policy and Analysis (Leithwood, 2003) asserts that the impact of school leadership is second only to that of the teacher in determining school effectiveness. Walters, Marzano, and McNulty conducted a study of the impact of leadership on student achievement (2003). After reviewing 30 years of research, they posit that the principal does indeed have a significant impact on achievement. Elmore echoes these sentiments. "Leadership is the guidance and direction of instructional improvement" (2000). Six research questions will be examined. Their aim is to determine whether or not rural and urban school principals perceive their strengths and weaknesses the same and to determine the best practices of these principals. The specific research questions will be as follows:

RQ1: Is there a difference in the LPI scores between principals in terms of "modeling the way" in urban and rural Ohio Schools of Promise?

RQ2: Is there a difference in the LPI scores between principals in terms of "inspiring a shared vision" in urban and rural Ohio Schools of Promise? 
RQ3: Is there a difference in the LPI scores between principals in terms of "challenging the process" in urban and rural Ohio Schools of Promise?

RQ4: Is there a difference in the LPI scores between principals in terms of "enabling others to act" in urban and rural Ohio Schools of Promise?

RQ5: Is there a difference in the LPI scores between principals in terms of "encouraging the heart" in urban and rural Ohio Schools of Promise?

RQ6: What are the best practices of rural and urban school principals in high performing and high poverty schools in Ohio?

To identify principals for this study, a list of the Schools of Promise was obtained from the Ohio Department of Education website. The list was then filtered to include only schools which won the award for at least the previous two academic years. From this list, all schools which were classified demographically as rural, urban, or major urban were selected as the population for the study. The principals of each of these schools were asked to complete the LPI survey. The scores resulting from the survey were the basis for determining interviews targeting best practices. Three teachers were interviewed from each of the ten buildings, resulting in a total of thirty interviews. The constant comparative method was then used as a means to identify emerging themes which were determined to be the best practices.

\section{Researcher Bias and Delimitations}

An inherent bias exists as a result of the researcher's current position as an educational administrator. Furthermore, the researcher has worked as an administrator in a school having been awarded the Ohio School of Promise distinction. Thus, a personal bias towards educational leaders in high poverty schools is likely to exist. Although this 
bias does exist, it also holds an advantage. The experience of being an active building level administrator in a high poverty school has granted the researcher a lens through which the problem of moving high poverty students to high levels of achievement can be closely examined. Additionally, while inherent bias may be present it will not have an effect on the description and analysis of the research findings.

The study is limited to several factors. First, the survey instrument is a selfsurvey. It provides a view of leadership from only one perspective. The research does not yield a 360 degree profile of leadership. Another limiting factor is that the sample is selective. Principals are not randomly chosen. Finally, the number of participants (sixty four) is relatively small. This is due to the focus on schools in Ohio. Thus, the ability to make generalizations from the study is limited. While the total number of participants is small, it does include 100 percent of the principals who have worked in Ohio Schools of Promise for at least two consecutive years. This fact strengthens the research.

\section{Significance of the Study}

Understanding what schools can do to close the achievement gap is of critical interest to multiple stakeholders. For school leaders (at both the building and district level) failure to close the gap can result in an array of consequences. Building level leaders' employment (and future employability) may be impacted by their record of closing the gap. In Ohio, for example, individual buildings receive ratings based on multiple indicators. One of those is AYP, which is directly related to closing the achievement gap. Failure to close the gap requires districts to take one or more corrective actions as suggested by the state. One acceptable action includes replacement of building leadership. The results of the accountability measures, which are made available to the 
general public, may play a role in the hiring process as well. A building level leader wishing to change jobs will have their success rate of closing the gap under great scrutiny by potential employers. An inability to close the gap may hinder job search efforts.

District level leaders have similar concerns as those of their building level colleagues. Failure to close the achievement gaps can strain the budget. This is a result of consequences established by NCLB. Districts may have to provide supplemental learning opportunities, such as lengthening the school day or school year, as a strategy for remediation. Such actions would almost certainly put a strain on the district budget. Offering school choice is also a corrective action for districts failing to close the gap. This may result in a decline in student enrollment, which would also have an adverse impact on the fiscal status of a district.

This study holds significance for academicians at the post-secondary level as well. Among their duties, they are faced with the task of preparing the leaders of the nation's schools. An educational leadership program which does not prepare students to address the achievement gap would be remiss. The students of a school can not afford to wait for a new school leader to learn what must be done to improve achievement for all. Each year of learning is critical. Thus, new school leaders must enter the job prepared to tackle one of educations most important challenges: eliminating the achievement gap.

Politicians and legislators at all levels have a vested interest in closing the achievement gap as well. Society as a whole would benefit from a more educated populace. Clearly, improving achievement levels for low income and minority students benefits everyone. A democracy depends on education as a means to promote equity. John Dewey (1916) promoted the importance of critical thinking and the spirit of 
working to solve common problems as vital to education in a democracy. As a society, we can not afford to ignore the achievement gap. We must do all we can to make it disappear. This study hopes to assist school leaders in their efforts to eliminate the achievement gap.

The purpose of this study is to examine building level leadership in high poverty/high performing (HP/HP) urban and rural schools in Ohio. Leadership traits and characteristics of principals in both types of schools will be examined and compared. A great deal of research has been conducted on leadership. In the past, correlating leadership traits with successful schools has been nearly impossible. However, the onset of testing and accountability, along with advances in technology, has made it easier to compare schools based on achievement test scores. These factors allow examination of schools which achieve at high levels against the odds. The focus of this study will be on the leadership profiles of the principals in these schools. Principals are the leaders of school improvement efforts, thus they must possess the knowledge and skills to lead. This study seeks to provide principals in urban and rural low SES schools with specific data relating to leadership behaviors, practices, and characteristics in successful low SES schools. Additionally, leaders in schools not classified as low SES may benefit. These schools may contain subgroups of students who are categorized as low SES. In order to make Adequate Yearly Progress under NCLB, these students must perform at the same level as their peers. Leaders of these schools may extract information from this study which could aide them in designing intervention programs to assist this subgroup of students to achieve at high levels. Finally, this study will add to the existing body of research pertaining to school leadership in general. Thus, it may be referenced by those 
involved with principal preparation programs. Closing the achievement gap gives students born into poverty a way to improve their socioeconomic status. Public education is a tool to provide equity and economic opportunity for the disadvantaged. An examination of how school leaders successfully close the achievement gap in both rural and urban settings for low SES students is of value.

\section{Summary}

An achievement gap has existed in the American educational system for many years. Recent political and social pressures demand this gap be eliminated, and that all students achieve at high levels. This study will examine the roles of leaders in schools which have successfully closed the achievement gap. A greater understanding of how the gap can be closed is beneficial to stakeholders at the local, state, and federal levels. Educators and political leaders are responsible for wiping helping all students achieve at high levels regardless of socioeconomic status.

The remainder of this document is divided into four chapters. The second chapter is a review of pertinent literature relating to general leadership theory as well as educational leadership in the areas of vision, culture, and the management of learning. In the subsequent chapter I will give a detailed explanation of the research methodology of this work. The results of the study will be reported in the fourth chapter, and in the final chapter I will summarize the results and discuss possible implications of the findings. 


\section{CHAPTER 2}

Review of the Literature

This chapter presents a literature review divided into five sections. The first section provides a brief historical perspective of the study of relevant leadership theory. The second includes an overview of educational leadership. An examination of research on effective low SES schools follows. The fourth section is a review of Kouzes and Posner's leadership profile. The chapter concludes with a brief summary.

Among the issues facing the educational system in the United States is the number of poor performing schools. Underscoring the problem of poor performing schools is the achievement gap which exists between low SES schools and their more affluent counterparts. The need for good leadership is essential in all schools. However, the leadership in schools faced with an achievement gap is even more critical as schools search for strategies to help all students perform at high levels. It is essential to have a deep understanding of the related literature focused on leadership theory, school leadership, how effective schools work, and good leadership in the context of high performing, low SES schools.

\section{Leadership Theory}

An early theoretical view of leadership espoused by Frederick Taylor was commonly referred to as scientific management. Taylor (1947) took a rationale approach to human behavior, and viewed organizations as machines. He believed there was a single best way to do anything, and this was the best way to maximize production and efficiency. According to scientific management, workers are inherently lazy and should not be allowed to determine output in any way. The job of management was to determine 
the best way to structure a task and then instruct workers on this method. Taylor advocated division of labor and specialization as a means to increase efficiency and eliminate waste. The role of the worker in scientific management was to follow the rules set up by management; worker judgment was unimportant. Planning and task execution were to always be kept separate. The scientific management model of leadership represented a clear, top-down approach with little interaction between or across levels, and little regard for individual needs, creativity, or interests. The scientific management approach was fitting for the industrial era in which it existed. Its influence can still be seen in many organizations. However, the underpinnings of scientific management are still evident in schools today.

Teaching specialization by content area is mandated at the secondary level. In many states (e.g. Ohio) a common curriculum exists based on a common set of academic content standards at each grade level. The notion of the Carnegie Unit as a common means to earn high school credit is also illustrative of the remnants of scientific management in the educational setting. Principals are responsible for insuring the school run in an orderly and efficient manner. Bell schedules are created, crisis and discipline plans developed, and master schedules constructed. The designs of such protocols demonstrate the usefulness of the scientific management approach.

As economic and societal changes evolved during the first half of the $20^{\text {th }}$ century, so did the opinions of what successful management (and leadership) should look like. The next era in leadership studies centered on behavioral and human relations theories. The importance of individual needs and the role of the social setting in the workplace underwent scrutiny. Human relations theorists sought to understand and explain worker 
motivation. Focus was drawn to the relationship of the leader to the workers and the resultant levels of productivity. Maslow developed the Need Hierarchy Theory consisting of five levels. Lower level needs include physiological and security needs. As these needs are satisfied, humans develop higher needs in the following order: sense of belonging, esteem, and finally self-actualization or self-fulfillment. Maslow posits that lower level needs must be satisfied before higher level needs become the focus, and that humans always strive towards the next higher level of needs. This theory of motivation suggests leaders be cognizant of individual needs beyond the most basic levels.

Educational leaders must understand the importance of putting the needs of children first. This becomes difficult for teachers when their own lower level needs are not met. The leader must be aware that factors such as school safety and school culture can impact teacher effectiveness. Factors that influence the lower level needs, such as school safety and school culture, impact teacher and learner effectiveness as well as leadership effectiveness. In the wake of recent episodes of school violence like the Columbine shootings, teachers and school leaders need to ensure safety to provide a healthy, fear free environment for both teaching and learning.

Elton Mayo’s Hawthorne Experiments viewed worker motivation as a function of the individual's role within a group. He linked worker productivity to morale, and saw the need for a sense of belonging and recognition as key factors impacting morale, even more so than physical conditions. Herzberg (1967) described motivation as being effected by two factors which he termed hygiene and motivation. Hygiene factors include organizational environment issues such as policies, structure of supervision, working conditions, salary, job security, and status. Motivation factors are intrinsic 
rewards such as recognition, advancement, and job interest. The lack of hygiene factors leads to dissatisfaction, and the absence of motivation limits the desire for personal growth. Thus, Herzberg maintains that leaders must build an organizational structure which responds to both hygiene and motivation factors to maximize productions.

The motivation-hygiene theory suggests principals consider a holistic view of staff relations. It underscores the importance of celebration and ceremony such as "teacher of the month" awards and staff appreciation luncheons. It also acknowledges the significance of environmental work issues like adequate supplies and planning time, a safe and orderly school, and creating clear and easily understood expectations for staff.

Human relations theorists focused on the relationships which exist among working groups rather than the relationship between the actions of the leader and the satisfaction and productivity of the workers. McGregor's Theory X and Theory Y explained the control of an organization as a function of the leaders' assumptions about human nature and motivation (1960). Theory X purports that people inherently dislike work and prefer to be directed. Motivation only occurs at the lowest physiological levels (safety and security) and must be closely controlled within the organizational structure. Theory Y counters that work is natural under the right circumstances, and people have a great capacity for creativity. They also are highly motivated by esteem and selfactualization, and they can be self-directed to perform and to seek out responsibility. McGregor believed that while many leaders operated under the assumptions of Theory X, those that espoused to the underlying principles of Theory $\mathrm{Y}$ were much more effective. McGregor believed the role of the leader was to be supportive and to obtain commitment from the workers, and to make their achievements feel appreciated. He offers an 
alternative style of leadership (Theory Y) to the traditional patterns of the scientific management past (Theory $\mathrm{X}$ ). The behavioral and human relations views of leadership reflect changes in the work environment.

As the $20^{\text {th }}$ century progressed, the number of occupations requiring interaction among workers and groups increased. Collaboration, teamwork, and communication became more valued skills. Management's view of the workforce changed. Human relations theory influenced leaders to enlist lower levels of the organization in their efforts to solve problems, and it led to the development of a more trusting and open work environment.

Educational leaders have been influenced by Theory Y in a variety of ways. Shared leadership and empowerment have become valued in school structure. District and building leadership commonly seek to include as many stakeholders as possible in school planning. Principals who garner teacher input with activities like textbook adoptions, technology purchases, and student grouping demonstrate Theory Y in practice. The empowerment of teachers in directing their own professional development activities provides another example of McGregor's ideas of management. These activities demonstrate a belief in worker creativity, and a need to strive towards self actualization.

The 1960's and 1970's also yielded contingency theories of leadership. These theories submit there is no single best style for leadership; the optimal style is determined by the external and internal factors of the situation. The work of Fred Fiedler (as cited in Hoy and Miskel, 2005) suggests that situational control, "the degree of power and influence that leaders have to implement plans, decisions, and action strategies" (p. 391), is determined by three variables. Position power indicates the ability of the leader to 
punish or reward followers, as well as the ability of followers to get rid of the leader. Task structure refers to the clarity of objectives. Leader-member relations consist of the level of acceptance and respect the leader has among the group, and it is the most important of the three categories for the leader's probability to achieve objectives. Fiedler also suggests that leaders can modify situations in order to change conditions to improve performance.

Educational leaders seeking to institute school reform should be aware that successfully implementing initiatives may not occur until the leader has established a foundation of respect and trust with the faculty, staff, and community. This point is especially important to a leader who is a newcomer to an educational setting. The principal can develop credibility by modeling good practice every day. Principals can teach a lesson to a class, meet with staff frequently, and survey the staff to measure their own performance as means to acquire acceptance from teachers and earn their respect.

Hersey and Blanchard have presented a contingency theory referred to as situational leadership (1982). The emphasis in this model is on the leadership activities in relation to followers. There is no single best way to influence others; leadership style ought to be determined by the maturity level of the followers. In this context, maturity level is defined "as the willingness of people to take responsibility for directing their own behavior" (p. 151). The maturity level is not constant; it is determined by the specific task or objective the leader is trying to accomplish. Hersey and Blanchard identify four types of leadership behavior: telling, selling, participating, and delegating. Thus, the leadership style chosen should be determined by the maturity level of the followers in relation to the task. For a low maturity relationship (an inability and unwillingness to 
take responsibility) "telling" is prescribed. "Telling" requires the leader to give clear and specific instructions. For a moderate maturity relationship (people who are willing to perform the task but are unable) a "selling" leadership style is proposed. This style is marked by a directive approach that is supplemented with ample support. When a moderate to high maturity level exists (followers are able but unwilling to accept responsibility), the suggested leadership approach is "participating." Such a circumstance is best addressed with a highly supportive but nondirective style highlighted by shared decision making and a facilitative role of the leader. "Delegating" is the preferred leadership for a high maturity relationship (which exists when followers are both able and willing to accept responsibility for a task). In this instance the leader maintains a low profile, lending little in the way of direction or support.

In the educational setting, examples of the need for different approaches are easily identified. The leadership exhibited with veteran teachers almost certainly should be different than that utilized with first-year teachers. Additionally, complex tasks such as the creation of a strategic plan or intervention policy require a different approach than something as mundane as the formation of a duty roster. Furthermore, principals use a different leadership strategy in determining when to conduct a fire drill compared to deciding strategies for the implementation of inclusion for special needs students. As educators seek to differentiate instruction for students, it behooves administrators to differentiate leadership styles when dealing with issues at the school.

More recently, leadership focus has frequently turned to the differences between transformational and transactional leaders. Burns is credited with popularizing the 
transformational and transactional terms (1978). He explains transformational leadership as:

whatever separate interests the persons might hold, they are presently or potentially united in the pursuit of high goals, the realization of which is tested by the achievement of significant change that represents the collective or pooled interests of leaders and followers. (p. 425, 426)

Transformational leaders appeal to higher ideals and values such as justice, equality, and equity rather than lower emotions such as fear, greed, or jealousy. Critical to the theory is the development of unity of organizational purpose, as well as the notion of forsaking individual goals for those of the group. Burns, however, applied his leadership theory primarily to the political realm.

Bass, building on the work of Burns, constructed a similar model of transformational leadership. His model was more centered on leadership in organizations outside of politics. Bass' model of transformational leadership (as cited in Yukl, 1991) explains that "leaders can transform followers by: (1) making them more aware of the importance and value of task outcomes, (2) inducing them to transcend their own self interest for the sake of the organization or team, and (3) activating their high-order needs" (p. 211). Bass also describes two other types of leadership: laissez-faire and transactional (1998). The paradox of laissez-faire leadership is that it can be characterized as a lack of leadership. Little dialogue between the leader and the followers exist. The laissez-faire leader essentially practices avoidance behavior through lack of interaction with followers as well as organizational problems. This style of leadership is least effective. Transactional leaders exhibit reliance on the exchange of 
rewards for services in order to accomplish organizational goals. All leaders must rely, at least to some extent, on this form of management. Transformational leadership is described as the ability of the leader to develop a sense of commitment among workers to each other, and to the goals of the organization. All members of the organization become interdependent on one another. The leader depends more on influence to accomplish goals rather than a systems of rewards and consequences.

School leaders make use of this theory when they collaborate with staff to develop vision and mission statements. Transformational leadership also is embedded within the idea of creating and sustaining professional learning communities within schools. Many schools, especially at the middle level, organize teachers into teams. This allows for common planning time. Such a structure is conducive to collaboration and interdependence. Leaders who promote interdisciplinary lessons or who implement coteaching strategies in an inclusive classroom setting are demonstrating transformational leadership at the building level.

Bolman and Deal developed a structure for studying leadership and leader behaviors (1997). Organizational leadership can be broken down into four frames: structural, human resource, political, and symbolic. The structural frame focuses on policy, rules, and roles within the organization. It seeks to improve the bottom line and relies heavily on the analysis of data. Improvement efforts are based on changes to the existing structure.

The human resource frame emphasizes the emotional and social needs of workers. Leaders operating through this frame look for ways the organization can better adapt to fit the needs of workers, or for ways to help the workers more easily assimilate into the 
organization. The human resource frame places great value on worker "buy in". Leaders are more likely to take a facilitative role, and they place great importance on empowerment.

The political frame views the organization as a competitive arena in which workers with differing interests vie for scarce resources. The result is a setting in which alliances are created. Changes in the organization lead to changes in the membership and role in the alliances. Negotiation and compromise become common place. This political environment requires leaders to have vision and the ability to forge positive relations with staff in order to be successful.

A leader focused on the symbolic frame views the organization in the context of the unwritten agreements, rituals, stories, and ceremonies that exist within it. These symbols guide behavior and are instrumental in developing loyalty and commitment. Changes in the symbolic framework of the organization may represent a shift in what is valued and accepted. Leaders must be aware of the power of symbolic activities and consider the ramifications of their continuation or elimination. The manner in which the leader deals with symbolic issues can impact their credibility and organizational improvement efforts.

School leaders benefit when considering the four frames during their decision making process. Principals use a structural and human resource approach when they form data analysis teams that target student performance on standardized tests. Clearly the goal is to improve future student performance. However, the formation of a team enhances collaboration and creates a sense of unity and singleness of purpose. Within the symbolic frame, the principal should see the value of attending events after school like 
athletic contests, band performances, spelling bees, and parent meetings. The political lens is one which building level leaders use frequently as well. Determining teacher schedules and planning periods, prioritization within the building budget, and the adoption or rejection of building initiatives are all areas which should be viewed through the perception of the political frame.

The ability to view the world through these frames assists educational leaders in their understanding of problems, thereby helping to guide their actions. Those who are unable to view the world through all four lenses are less likely to effectively analyze and solve organizational problems. Building and district leaders who are capable of seeing problems through different perspectives can generate several potential courses of actions and predict their likely consequences. The desired end result is increased student achievement.

\section{Educational Leadership}

The job of building level school administrators has grown more complex in recent years. Sherman (2000) provides a vivid description of the principal's role:

Research tells us that principals are the linchpins in the enormously complex workings, both physical and human, of a school. The job calls for a staggering range of roles: psychologist, teacher, facilities manager, philosopher, police officer, diplomat, social worker, mentor, PR director, coach, and cheerleader. The principalship is both lowly and lofty. In one morning, you might deal with a broken window and a broken home. A bruised knee and a bruised ego. A rusty pipe and a rusty teacher. (p.1) 
The role of the principal has changed in the age of accountability and school reform. The traditional roles of planning, organizing, and managing have been augmented by competencies and proficiencies (Sergiovanni, 2006). In part, this has led to a set of standards established for what school leaders should know and be able to do.

The Interstate School Leaders License Consortium (ISLLC) has established a set of six standards that are recommended as a guide for beginning and veteran principals. In broad terms, they include leadership competencies in: vision, culture, management of learning, community relations, ethics, and political and legal awareness. This framework for school administrators is meant to be used for administration preparation, mentoring of new administrators, and professional development and evaluation of current administrators (Hessel and Holloway, 2002). Given the context of this study, the literature review will focus on the principal's role in three areas identified in the ISLLC standards: vision, culture, and the management of learning. The impact of leadership on student achievement will briefly be discussed.

\section{School Leadership and Vision}

Vision is a useable guide for school leaders (Leithwood, 1994). It is used to assess the overall status of the school. The current state of the school is compared to the vision of what the ideal school should look like. The discrepancy between the two images establishes the grounds for action. Visions are most effective when they are widely shared. The development of the vision should be a shared process and should be carefully thought out. It can have some broad characteristics which apply to most schools, while including aspects which are unique to the particular building setting. The development of the vision should take into consideration research on the characteristics 
of effective schools, and should consider trends in society and the education profession as a whole. Visions which are collaboratively created, take into consideration the unique aspects of the school, and are grounded in research become a tool which is useable for the school leader.

Neuman and Simmons (2001) posit that a shared vision is one strategy that will improve student achievement. The vision should have clear goals and should focus squarely on improving student achievement. The role of the leader in facilitating the vision is to model it in everyday words and actions and to keep the staff focused on it as a daily guide.

DuFour and Eaker (1992) outline three major benefits of vision statements. First, the vision acts as a motivational device. It is very visible and made public, so members of the organization have a constant focal point. Secondly, the vision provides direction for individuals. It makes it easier for them to find their role within the organization, and it sets up guidelines for behavior. Finally, the vision helps the school set an agenda. It helps chart a course of action to eliminate the gaps between the reality of the current state of the school and what the ideal school, as described in the vision, should look like.

It is vital for the school leader to reach a consensus with the school community on the vision statement. Development of the statement should be the work of a task force created for just that purpose. The group should be made up of representatives from all constituents of the school community (DuFour and Eaker, 1992; Lambert, 2003). The group should include teachers, parents, community members, students, etc. Those on the task force should be influential members of the group they represent. Also represented on the committee should be a member of the school board or the district administrative 
team. When finished, the vision statement must contain four characteristics: (a) it must be written; (b) it must be widely disseminated; (c) the vision should have widespread support from the school community; and (d) it should be a statement that can be used as a day-to-day guide for behaviors within the school. In order for a collaborative work environment to exist, a shared vision must be in place.

The principal is constantly immersed in situations which grant an opportunity to convey the vision of the school (Kochanek, 2005). Every interaction must be viewed as a chance to gain information about the community and staff, as well as an opening to articulate the vision. Reeves (2006) emphasizes the importance of visionary leadership in schools. "The first obligations of leadership are articulating a compelling vision and linking clear standards of action that will accomplish the vision" (p. 34). The vision should be a guide in tackling both large and small tasks. Vision statements should act as a blueprint, and can be used to build trust. A clear vision helps leaders respond to difficult questions with clarity and consistency.

A shared and clear vision is important in schools affected by high poverty rates. The learning community in these schools is faced with complex problems. The vision reminds all stakeholders to focus on the "big picture", which is student achievement. It is a helpful guide in difficult times and helps create unity of purpose. The school's vision should be reflected in the school culture.

\section{School Leadership and Culture}

Many definitions exist for school culture. It consists of numerous things. Barth (2001) describes culture as a "complex pattern of norms, attitudes, beliefs, behaviors, values, ceremonies, traditions, and myths" deeply embedded within the organization. 
Culture holds tremendous power, and influences how people think and act within the organization.

Deal and Peterson (1990) acknowledge school culture is difficult to define. It can be sensed immediately as one enters a building. It consists of the pictures on the walls, the conversations of students, the dialogue between the teachers, and the looks of the students. School culture describes the character of a school. It is the deeply held values, patterns, beliefs, and traditions of a school. Culture is, in a sense, taken for granted. It is the unspoken guide for people's actions, and helps give meaning to what they do.

Fullan (2003) explains the role of the school leader in developing a performance oriented culture. The principal must develop three types of trust with the teaching staff: competence, contractual, and communication. Competence trust refers to the principals' respect of teachers' knowledge, skills, and judgment. Should the principal lack faith in the competence of a teacher, it becomes their responsibility to get the teacher help or get rid of them. The principal must be willing to seek the input of teachers as well. This is another form of competence trust. Contractual trust is the principal's need to be consistent, establish boundaries, and honor agreements with teachers. Honesty, the sharing of information, maintenance of confidentiality, and the ability to give and receive constructive feedback are all part of communication trust. A collaborative culture in a school can not exist unless the types of trust listed above are in place.

Dufour and Burnett explain that school leaders must not only cultivate positive cultural norms, but they must also "weed out" the negative elements of culture (2002). School leaders should create the conditions necessary to improve the self-efficacy of teachers. They must also challenge the beliefs of those teachers who believe teachers are 
not responsible for student learning. The leader can address these areas with teachers by sharing research which proves otherwise. The work of schools and teachers does make a difference in student learning. Leaders need to also celebrate successes of faculty in order to improve school culture. They must fight teacher isolationism by promoting a collaborative culture. This can be done by arranging teachers into academic teaching teams, and by embedding collaborative planning time within the structure of the school day. The principal must monitor the work of these teaching teams and celebrate their successes. School leaders should develop a guiding mission of the school and work to keep the staff focused on it. This mission acts as a unifying instrument which aligns stakeholders towards a common goal. Finally, a positive culture is one which focuses on results. Educators are frequently barraged with new ideas and initiatives. The leader must focus the energy of the staff towards a few important initiatives. Then, targets and timelines should be established to help maintain the focus. Emphasis should be placed on results, as opposed to activity. To conclude, the principal must always keep in mind that the task of sustaining a positive school culture is on-going.

Barth (2002) explains that while a school's culture can either help or hinder improvement efforts, existing cultures are almost always resistant to change. To change a culture the leader must first develop a keen awareness of it. In particular, the principal must pay close attention to "nondiscussables". Nondiscussables are important topics about the school which are only addressed in small informal groups due to the anxiety they cause. Nondiscussable topics include things such as: leadership of the principal, mediocre teachers, race, etc. To change a school culture, the leader must be able to make the nondiscussables part of public discussion. The greatest challenge of a school leader is 
to transform toxic cultures into positive ones which promote lifelong learning among adults and students.

Leaders play a vital role in shaping school culture. According to Deal and Peterson, the school leader has eight symbolic roles in the shaping of the school's culture (1999). As a historian, the leader should have knowledge of the background of the school. Staff members should be reminded of where the school has been and the crises or challenges from the past which have shaped current practice. School leaders must be visionaries as well. They must frequently communicate to stakeholders the hopes and dreams of the school. In doing this, the leader maintains a focus on the vision and mission of the school. Additionally, school leaders are symbols of the school itself. They are constantly watched by staff and students alike. The actions taken by the leader signal what they value. Tasks which are routine in nature often take on great symbolic meaning. For example, the visibility and accessibility of the principal to staff and students takes on great significance. The amount and types of interaction between the school leader and staff and students also sends a message to those stakeholders. School leaders are also cast into the role of actor. During critical incidents the leader has an opportunity to reaffirm or alter existing values. Principals must use critical events as a springboard, and should not avoid them. The role of healer is also identified as important to the school leader. In this role, the principal helps stakeholders adapt and cope in times of transition. This includes events such as the opening and closing of the school year. This role also relates to the lives of staff and students. Principals must recognize the difficulties posed by transitions, and work to make them a collective experience rather than one which is divisive. 
Understanding the culture of the learning community of an HP/HP school has great value. It gives insight into why things exist as they do, why initiatives fail, and helps identify the barriers to success. The leader who understands the school culture has a better chance to successfully implement improvement programs. They have knowledge of who can help or hinder efforts, and they understand what is valued by members of the learning community. A school leader equipped with an understanding of the power of school culture and the value of a shared organizational vision must also possess skills in the management of learning to successfully develop and maintain an HP/HP school.

\section{School Leadership and the Management of Learning}

The management of learning, ISLLC standard number three, includes the procedures and management decisions a principal must implement to ensure successful teaching and learning. Professional development is an important component of school improvement initiatives, and it is a common theme in the research of successful at-risk schools. Schools are filled with teachers who have varying degrees of effectiveness. Since it would be virtually impossible to eliminate all teachers who are marginal, something must be done to improve their performance. Thus, professional development plays a pivotal role in school effectiveness. According to Hirsh, effective professional development strategies have three common elements (2005). Teachers must develop an extensive and deepened understanding of the content they teach. Strengthening pedagogical and other skills will have a limited impact unless teachers further their knowledge of their content area. Professional development also should include thorough conversations about core beliefs and values held by teachers. The only way to change teacher behavior is through a modification of teacher beliefs and assumptions about 
teaching and learning. Finally, effective professional development should consist of a detailed plan which also includes continuous feedback and follow up. There is no single best professional development plan for every school. However, the plan should include the previous three attributes if it hopes to close the achievement gap.

To sustain professional development in schools, the evolution of the professional learning community (PLC) has become desirable. Dufour (2005) posits that PLCs consist of three essential elements. First, schools must shift their focus from teaching to a focus on learning. Simply put, teachers are not responsible for what they teach as much as they are for what students learn. Secondly, a hallmark of a PLC is a commitment to staff collaboration. Teachers and administrators work together to solve problems in a systematic fashion by analyzing problems, brainstorming solutions, and supporting each other in a quest for improvement. Finally, the PLC is driven by a focus on results. The process involves a determination of current levels of student achievement, establishing goals for improvement, working together to meet the goals, and assessing formatively and summatively to track progress. DuFour (2002) suggests the traditional title of the principal as "instructional leader" be changed to that of "learning leader" to more accurately reflect the emphasis on student learning rather than teacher instruction.

In support of PLCs, Schmoker warns that isolation is the enemy of improvement (2005). Collaboration is the surest way to improvement. Isolation, on the other hand, grants so much autonomy that teachers can instruct as poorly (or as well) as they wish. Teachers learn best not from some outside source, rather they learn best from each other in their own school setting. The role of the principal must shift accordingly by taking on a facilitative posture. Leaders must provide the opportunity for teachers to improve their 
own instruction, and then play a supportive role in such teacher improvement initiatives. The principal assists by participating in teacher discussions and by helping to monitor (formatively and summatively) student achievement.

Dennis Sparks (2005) too espouses the benefits of PLC's, and notes the important role principals play in their development and sustainability. Sparks contends that of all the effort at the federal, state, and local levels to improve instruction, the two percent that occurs at the building level has the greatest impact on teaching and learning. It is important to note that "the quality of teaching, learning, and relationships in professional learning communities depends on the quality of leadership provided by principals" ( $\mathrm{p}$. 156). While barriers to the development of PLCs exist, the ability of school leaders to overcome such barriers is their most critical duty.

School leaders are increasingly faced with the challenges of accountability (Leithwood, 2004). To meet these challenges, principals must be able to create and sustain a competitive school. Public education is faced with threats from charter schools, magnet schools, voucher programs, and private schools. A direct competition for students is reality for most schools, and they must be ready to respond. Leaders also must be willing to permit community input in major decisions. The support of these stakeholders is necessary for successful schools. The leader should provide instructional guidance in the form of quality professional development, and must successfully develop and implement school improvement plans. Principals must be sure that improvement initiatives target groups such as minorities and special needs populations. Equity is a focus in the age of accountability and standards. Finally, school leaders need to practice 
distributed leadership in order to be successful. The job of school leadership is too large for one person to handle successfully. As Reeves (2006) eloquently states:

The challenge of educational organizations is not to make these leaders into perfectly complete beings by filling in their deficiencies, but rather to create an environment in which the leaders are empowered to create complimentary teams. Although no single leader will possess every dimension of effective leadership, the team will surely do so (p. 29).

Walters, Marzano, and McNulty conducted a study of the impact of leadership on student achievement (2003). After reviewing 30 years of research, they posit that the principal does indeed have a significant impact on achievement. Importantly, the impact can be either positive or negative. Two variables determine whether leadership will have a positive or negative impact. First, whether or not the principal accurately identifies and focuses on the correct school and classroom practices necessary for increased student achievement is critical. Improvement efforts must be targeted in the right direction, or a negative impact on student achievement may occur. The second variable is the magnitude of change. Change impacts some people different than others. Two "orders" of change exist. First order changes are those that are basically consistent with existing knowledge, resources, and practices. They are changes that are generally agreed upon as necessary. A change which requires new approaches or procedures which conflict with existing values and norms is second order. A change could be first order for some staff but second order for others, depending on the individual's values, beliefs, and assumptions. School leaders must recognize how change and improvement initiatives are viewed in order to accurately select their leadership practices. First order changes require 
staff cooperation, a sense of well being, and cohesion among staff. Second order changes will require the leader to develop shared understanding of the purpose and vision of the school.

The Center for Educational Policy and Analysis asserts that the impact of school leadership is second only to that of the teacher in determining school effectiveness (Leithwood, 2003). Successful school leaders set the direction of the school by articulating the vision, and focusing all staff on achieving its goals. These leaders set high expectations, and regularly monitor the performance of the school. Effective school leaders also tend to the human resource aspect of the school. They challenge and stimulate staff members to reflect on current practices, and they provide resources needed for professional enrichment. In addition, they model the vision and mission of the school, which becomes a positive and reinforcing set of behaviors for teachers to view. Finally, the effective school leader develops the organization of the school as a whole. A positive, supportive culture is nurtured, and the context in which teaching and learning takes place is carefully established and monitored.

Carter reported on the leadership efforts of seven principals in schools having greater than $75 \%$ free/reduced lunch rate that exhibit high academic achievement (1999). The principals of these schools all had great autonomy in terms of how to spend money, whom to hire, and how to teach. These leaders had the flexibility to institute new programs and to take academic risks. They also established high, measurable goals which include the entire school, and teachers are personally held accountable for achieving the goals. Goals were accompanied by frequent short cycle testing, and the 
principals personally monitored test results. Finally, the principals of these schools successfully involved parents with the academic mission.

In a similar study, Teske and Schneider (1999) conducted interviews of principals in eight successful schools in New York City. They discovered four common themes among the building leaders. They all had control of the hiring practices as well as the staff development programs in their buildings. In addition, the principals were able to successfully rally the school community around a specific mission. While the missions of the buildings varied, the importance of a common focus within each school community seemed to be important. Thirdly, high expectations for both students and staff were prevalent. Finally, the principals of all eight buildings were considered to be experienced.

While a shared vision and a healthy school culture are essential elements for creating an HP/HP school, they are not enough. School leaders must understand the management of learning to facilitate a process for attaining high achievement within the context that is created by the vision and culture. Educators must be in the process of continuous improvement; it is the principal's job to create the conditions to allow this to occur. Understanding the management of learning is valuable for principals working in high poverty schools, but it is also of value for any administrator with a subgroup of high poverty students in their building. As noted previously, NCLB requires subgroups of students to make AYP or consequences may follow. School leaders who lack knowledge of ISLLC Standard Three, the management of learning, are unlikely to guide schools challenged by students of poverty to high levels of achievement.

High Performing, High Poverty Schools 
The primary goal of public education is academic achievement for all students. Schools have varying levels of success in reaching this goal. They are also unique, consisting of a teaching and learning community that is diverse in background, skill set, and knowledge made up of all of the possibilities variations in background, skills, personality. The common characteristics of high performing schools have been the subject of researchers for many years. The bulk of effective schools research has been conducted with schools exhibiting high poverty students, a high minority student population, or both. However, there has been some examination of high performing schools without regard to these characteristics.

The Coleman Report, issued in 1966, was one of the most prominent and influential pieces of educational research of its time. In essence, its findings suggested that the strongest predictor of academic achievement was family socioeconomic status. The report inherently minimized the impact of schools in determining student achievement. Not long after the report was issued, many educational researchers set out to debunk its conclusions. A second wave of research was conducted following the publication of A Nation at Risk in 1983. The content of this report has led to large scale school reform at the local, state, and federal levels. It certainly could be seen as the beginning of the accountability movement in education. The report set into motion the wheels of accountability for public education. With the wave of accountability, the achievement gap was in the forefront. As schools and districts were confronted with the problem of closing the achievement gap, interest in high performing, high poverty schools was once again heightened. 
Several studies were conducted during the 1970's about high performing, high poverty schools. In 1971, the Council for Basic Education studied four high poverty New York City elementary schools which had above average achievement in reading (Weber). Eight factors were identified which existed in the successful schools that were not evident in unsuccessful inner-city schools. They included strong leadership, high expectations, good atmosphere, individualization, and frequent use of assessment. A similar case study was conducted by the New York State Office of Education Performance in 1974. Two high poverty schools with comparable demographics, one highly successful in reading and the other high unsuccessful, were studied. The differences in achievement levels were attributed primarily to school administration. More specifically, the administration in the successful school was able to solicit greater cooperation from staff, students, and parents. The successful school clearly targeted high scores on a reading achievement test as an objective, while the unsuccessful school lacked this focus. Additionally, the successful school was run more efficiently and orderly by administration. Other than achievement levels, "the quality and attitude of the administration seemed to be the only real difference between the two schools" (p. 63). Beginning in the late 1970's, Lawrence Lezotte, Ronald Edmonds, and William Brookover conducted a series of studies focusing on HP/HP schools which became the precursor to the Effective Schools Movement. Brookover and Lezotte (1979) studied two groups of schools: one set had steadily increasing achievement while the other was characterized by declining achievement. The improving schools shared some common characteristics. They all had clearly focused goals towards reading and math achievement. In addition, an attitude of high expectations by the teachers was pervasive. 
This resulted in a sense of assumed responsibility among teachers for the education of the children. The staff did not blame external factors for student failure. Ronald Edmonds was the first to identify the correlates of effective schools (1979). The characteristics included:

1. Strong administrative leadership;

2. a climate of high expectations;

3. an orderly atmosphere;

4. an emphasis on basic skills; and

5. frequent monitoring of student progress.

While these correlates were later refined, they became the basis for the Effective Schools Movement. They now include positive home-school relations, clear and focused mission, and opportunity to learn or time on task (Lezotte, 2008).

One of the outcomes of the emphasis on accountability has been an increase in the amount of research on HP/HP schools. The Charles A. Dana Center at the University of Texas reported their findings of nine high performing, high poverty schools (Johnson and Asera, 1999). They discovered some differences these schools had when compared to their high poverty and low achieving counterparts. In each school, the principal began by targeting an important, visible, and attainable goal. Once this goal was achieved, it paved the way for future successes by changing the mindset of the school community. The principals also were able to refocus the energy of the staffs to children. Most of the buildings were characterized by adult bickering. The administrators were successful in getting the staff to think of the school as more student centered rather than teacher centered. 
The schools studied had few discipline problems. Students took responsibility for their behavior. Clear rules and expectations were set, and consequences were consistent. The school staff was highly visible at all time to reinforce policies. Also, reward systems were in place to encourage positive behavior. The HP/HP schools had leaders who devoted more time to instructional problems than in other schools. They developed a collective sense of responsibility for improvement by involving everyone in the planning process. Instruction was aligned to state standards, and data was used to refocus on areas in need of improvement.

Other common factors existed as well. Strong partnerships were built with parents and the community, and extended learning time was generally offered. Time was generally structured to nurture collaboration around instructional issues, and teachers were supplied with all the resources, training, etc. needed to be successful.

Interesting discoveries have been made about the lack of an achievement gap among students attending school on U.S. military bases (Viadro, 2000). Blacks and Hispanics in overseas Pentagon run schools score significantly higher than there counterparts in the states. In some NAEP tested areas they rank first when compared to their peers in the 39 states that take the test. While a gap exists between their achievement and the achievement of white students, it is significantly less than in the states. Notably, students in overseas Pentagon schools face many of the same obstacles as do minority students in the states. There is a high mobility rate, and often times a parent is called for duty and is gone for months at a time. And, while they are guaranteed medical care and housing, many of the students still qualify for free and reduced lunches. Parent and community support is high at military schools. Parents are strongly 
encouraged and expected to attend parent-teacher conferences, and the military base provides a community support structure. Curriculum is standardized, so that students moving from one base to another have an easier transition. Student expectations are high, and nearly $75 \%$ of all graduates go on to college. Programs for struggling students are in place, and coursework has become more rigorous. Graduation requirements have been raised, and all basic high school courses have been eliminated. All students must take algebra and trigonometry as well as two years of foreign language and three years of science. Teachers on the overseas bases are well qualified, and in most instances are more educated than teachers in the states. Teachers typically have master's degrees and maintain longevity in the profession on the bases. While the military setting is certainly different than anything civilian students' experience, the success the military has had closing the achievement gap is worth consideration.

The Golden Spike Award is given in Illinois to high poverty, high performing (HP/HP) schools. McGee (2003) conducted a study of fifty nine schools awarded the distinction of the Golden Spike, and found many commonalities. Teachers and administrators in the recognized schools used data extensively. The data collected was part of internal as well as external accountability systems that were put into place. External accountability includes the state assessment required by all schools. The internal piece was part of community surveys, local assessments, or nationally normed tests. Most schools had a specific process for collection and data analysis. The information obtained was used to guide instructional decisions to improve standardized test scores. The teachers in the high performing/high poverty (HP/HP) schools were also noted as outstanding. They had common beliefs that all students could learn, and this 
was demonstrated in a team spirit which seemed to exist. The teachers were also quick to innovate by using new resources or instructional strategies.

The staffs in these schools had a strong work ethic, and the culture of each school was characterized by a family like bond. Teachers often spent their own money for resources, and it was not uncommon for them to make home visits. Many teachers worked extended hours, but did so because they felt it was necessary to get the results they wanted. The staff supported each other and celebrated successes in a collective manner. Cooperation and communication were a hallmark in the schools.

The Golden Spike schools were aggressive in seeking out parent involvement. Many schools offered parenting classes, and families were frequently invited into the buildings. Communication was free flowing, and many staff members gave parents their home phone number and/or e-mail addresses. The teachers recognized that extra effort was necessary to connect with the parents, and they were willing to take the steps necessary to create the link. The Golden Spike schools also had a strong focus on professional development. Staff development is on site, and it is tied into the school improvement plan. All staff participates, so this gives a common body of knowledge to work with, and it further enhances the spirit of team and family within the buildings. Additional characteristics of the schools include increased learning time (e.g. after school programs), focus on health and safety issues, and implementation of early childhood education programs.

A 2003 study examined the differences in classroom practices in Kentucky schools, comparing those with high achievement gap to those with low achievement gaps (Meehan, et al). The schools were all classified as high performing, but half of them had 
subgroups (socioeconomic and racial) where large achievement gaps existed.

Differences were found in how classroom time was used. The minimum gap classrooms spent less time on administrative functions and more on instruction. Pace in the minimum gap classes was more appropriate, and more student led activities were utilized. Textbooks were used more frequently in minimum gap schools, and more multi-racial instructional materials were used by the teachers. Differences in classroom climates were apparent as well. The minimum gap schools had more cheerful environments which were more inviting to risk taking. There were fewer distractions in the rooms, and the teachers showed a better sense of humor. Clear differences among expectations and feedback also existed. In the minimum gap schools, high expectations were communicated, there was more assessment, and feedback was more immediate. Instructional differences were apparent as well. The minimum gap schools had higher quality of instruction, and topics were more often related to students' lives.

The Learning First Alliance conducted a study of five high performing school districts which were high poverty and diverse in their populations (Tongeri, 2003). The districts all had made significant achievement gains in math and reading. Several key findings were made. Among those were:

1. District leadership publicly acknowledged the poor performance of the schools and accepted responsibility. There was no blame, and the focus was on working together to find a solution.

2. Changes were in instruction took place system wide. Fundamental changes were made in the way teachers taught, and school administration at all levels would need to find better ways to provide support. 
3. Each district had a vision which centered on increasing achievement, improving instruction, creating a safe environment, and more parent involvement.

4. Data was the guide for all decision making.

5. The face of professional development was changed. All activities focused on student achievement, and increased internal networking and collaboration was developed.

6. Leadership became more distributed. No single entity could alone find a way to make the changes necessary to close the achievement gap.

7. The districts were committed to change over a long period of time. They recognized improvements would take time, and they were determined to stay the course. Reform efforts lasted even when administrative leadership changed.

The reasons for achievement gaps are many, and they require complex and varied solutions (Legler et al., 2004). Four studies funded by the Learning Point Associates found that the use of data is vital to reducing the gaps and increasing student achievement. Standardized tests play an important role in analyzing student performance. However, the development and use of assessments at the classroom level is even more important. Early intervention plays a critical role in student success. Classroom level data helps teachers identify students in need of remediation, and provides information about modifying instruction. In order for teachers to effectively use data, ample professional development must be available, and time embedded during the regular school day should be available for teachers to examine data. It also appears that 
school improvement strategies should be focused, and centered on one or two improvement initiatives. Schools using several unconnected strategies routinely fail to make gains in student achievement. The studies also suggested the importance of teacher support and encouragement as a factor in closing achievement gaps. Notably, many factors relating to students (such as income, background, etc.) are relatively steady. However, the relationships students have with their teachers can change. Therefore, this is a variable that can not be ignored.

A recent study conducted by the United State Department of Education (2005) examined four large public high schools with a large minority population. These schools all had a four year record of narrowing or closing the achievement gap. Several common themes among the schools were discovered in three areas.

\section{School Culture}

Each school had a culture of high expectations. The virtual elimination of remedial courses reflected this belief. Advanced course replaced the remedial ones, and students were encouraged to enroll. Administrators served in the role of facilitators to help staff make necessary changes. Learning support systems were in place in all the schools. They took the form of tutoring and study skills classes for students and professional development opportunities for adults. Accountability played an important part in each building. Teachers were well aware of state and classroom test scores, and used this to drive intervention and revision of lessons. The buildings were also characterized by collaboration among staff members and with administration. 
Teachers worked together on innovations, and principals provided all support materials.

2. Curriculum and Instruction

All the schools went through a curriculum alignment process to carefully match state standards. Test scores were examined to determine which areas were deserving of more focus or needed to be taught differently. The structure of the school day became a variable as well. Schedules were altered to allow additional time for instruction and practical application. Finally, teaching staff in the schools used a variety of techniques which engaged students in learning. Classroom activities which made lessons more meaningful and relevant to the lives of students were the focus. Teachers used hands on activities, allowed time for student discussion, used technology as a tool, and differentiated instruction.

\section{Leadership for Change}

School personnel viewed change as arduous, but also as a necessity. The urgency for change was established by looking at data. Efforts towards change were led by administrators in some cases, and by teachers in others. All change efforts involved a core of people at the building level. The resources needed to study and implement changes were always viewed as the responsibility of the principal.

Haycock discusses what lessons have been learned by schools which have successfully closed the achievement gap (2001). First, standards are critically important. Traditionally, students in high-poverty, high-minority schools do not get challenging 
work. Standards have helped to change that by acting as a guide. They tell parents, students, and teachers what skills need to be mastered. They insist that all students achieve. Standards are not effective, however, unless they have a challenging curriculum to accompany them. More students need to take college prep curriculum. The more vocational type courses a student takes the more likely they are to score lower on the National Assessment of Educational Progress test. A rigorous curriculum is as important for work bound students as it is for college bound ones. Another strategy in closing the achievement gap is extra help for students. Supplemental instruction needs to be offered during the school day, before or after school, on weekends, or during the summer to get students to grade level. Finally, the quality of teaching matters. In high poverty schools, students are more likely to be taught by teachers who do not have a strong background in the content area they are assigned. If standards do indeed matter, then leaders must ensure teachers are knowledgeable about the subjects they teach.

The Appalachia Educational Laboratory (2005) conducted a case study of six high performing schools in Tennessee. The findings identified several common traits. The schools held a culture of high expectations for both student and teacher performance. The curriculum used was closely aligned with state standards. Additionally, multiple assessment strategies were used, and instructional efforts were driven by data based on those assessments. Teaching and learning were clearly the focus of these schools, and a high level of parental and community interest were obvious. The schools in the study were not characterized by high poverty. However, it is interesting to note the common features of these schools with HP/HP schools. 
The School of Promise Award is bestowed upon HP/HP schools in Ohio. The Ohio Department of Education (2008) cites five lessons learned from case studies of these schools. First, students are held to rigorous standards and the curriculum is vertically aligned. There is widespread use of various assessment practices, and data analysis is conducted on a regular basis. Secondly, collaboration among teachers and between teachers and administrators is common. The responsibility for student learning is shared among teachers and administrators alike. Third, at-risk and special needs students are expected to learn at high levels. To accomplish this, the schools utilize inclusive practices and they strive for immediate intervention for students who struggle. Fourth, the schools actively seek the support of the parents and the community. They offer parent support programs and use multiple methods to communicate with families. Finally, the schools create a culture of caring in the school. Reward and recognition programs are in place, and discipline policies and procedures are clear and consistently followed.

A recent analysis of HP/HP schools (Shannon and Bylsma, 2007) identified nine characteristics of such schools, but noted that all schools did not necessarily possess each one. Each school, however, appeared to have at least five of the characteristics. The nine characteristics were listed as:

1. A clear and shared focus

2. High standards and expectations for all students

3. Effective school leadership

4. High levels of collaboration and communication

5. Curriculum, instruction, and assessments aligned with state standards 
6. Frequent monitoring of learning and teaching

7. Focused professional development

8. A supportive learning environment

9. High levels of family and community involvement

Notably, effective school leadership is singled out as being essential in the implementation of the other eight characteristics.

Barth et al report on a study of HP/HP schools conducted by the Education Trust (1998). The study was completed by principals and involved 1,200 schools. Among the schools, 366 were from 21 different states and considered to be largely poor. The schools were either classified as operating in rural isolation or in an overcrowded urban area. Furthermore, the schools were all categorized as high achieving or greatly improved. Six major findings were discovered.

The most significant of the findings was the extent to which the high poverty schools used standards to guide instruction. Classroom instruction was closely aligned with state standards. Over half the schools also reported they used standards in the teacher evaluation process. This practice helped to strengthen the alignment of curriculum. Another finding showed that the HP/HP schools implemented some sort of extended learning time in core academic areas, especially reading and math. Time was made either during the regular instructional day in the form of blocked classes or enrichment classes, or after school programs were in place. Interestingly, the type of math instruction in the classroom seemed to make a difference. The high performing schools had moved away from low level instruction (i.e. ditto sheets) and increased 
discussion of subject matter and use of technology for instruction. The emphasis was directed more towards higher order thinking skills.

Other findings of the study show the HP/HP schools allocate more professional development money towards standards based instruction. Most of the PD was in the areas of math and literacy. The high performing schools also distinguished themselves in the way they monitored student learning. Some type of formative evaluation was in place to identify students in need of early intervention. In some cases, weekly progress reports were sent home. The HP/HP schools also report that they operate in states where accountability structures are built in at the state level. These systems held teachers and principals accountable for student learning, and applied sanctions where achievement was not considered adequate. A final discovery through the study was in reference to parent involvement. Not only did the high performing schools have more parent involvement, but the type of involvement differed. These schools worked to involve parents in academic areas rather than just extracurricular ones. The focus was on increasing parent knowledge of the standards and a deeper understanding of student work.

The Kouzes and Posner Leadership Practices Inventory Kouzes and Posner have developed a Leadership Practices Inventory (LPI) which has its roots in the early 1980's (Kouzes and Posner, 2003). The LPI began as a research project examining what leaders did when they were at their peak performance. Kouzes and Posner conducted hundreds of reflective surveys from outstanding leaders in all types of organizations. The results led them to develop five practices of exemplary leadership. A quantitative instrument consisting of thirty statements was then developed to measure 
these leadership practices. The questions are designed to examine behaviors reported when leaders were at their very best.

Kouzes and Posner submit that leadership consists of practices which all people are capable of learning. Leadership is not something that is limited to a relatively small percentage of people; it is not genetic. Ordinary people can develop into effective leaders. Consequently, the development of leadership qualities is ultimately about the development of oneself. Kouzes and Posner's (2002) five practices of exemplary leadership are:

1. Model the way,

2. inspire a shared vision,

3. challenge the process,

4. enable others to act, and

5. encourage the heart. (p. 13).

Each of these leadership practices consist of two corresponding commitments. The following portion of this literature review briefly examines the five practices and their corresponding commitments.

Model the Way

Leaders must have credibility with followers to be most effective. Credibility is earned. An important way the leader can earn credibility is to stand up for their personal beliefs. To model the way, leaders must do what they say and lead by example. Their deeds must be consistent with their words.

Commitment one: clarify values. The first step in modeling the way is for the leader to clarify their personal values. Those who are not clear about their beliefs are 
more likely to change positions or be swayed by the latest trends. People tend to admire those who have clear and strong convictions. "You can't believe in the messenger if you don't know what the messenger believes in" (p. 48). Values influence all decisions and act as guides. They tend to empower and motivate people.

Commitment two: set the example. Values become tangible when actions are aligned with them. Leaders signal what is most important to them by how they spend their time. They also must work to cultivate a shared set of values among the group. Employees are more loyal and work harder when their values and those of the organization are the same.

Inspire a Shared Vision

Leaders who are forward looking are generally admired. They are concerned not only with the problems of the present, but also the possibilities of tomorrow. Those who are intrinsically motivated towards high performance are self-inspired people, and it takes an inspired person to inspire others.

Commitment three: envision the future. Leaders find ways to create a common vision for organizational success. They think proactively about the future; they think about the possibilities and not the probabilities. Leaders use vision to create a stronger sense of purpose and commitment to the job at hand.

Commitment four: enlist others. Leaders must effectively teach and communicate their vision to others. Members of the organization must understand and accept the vision in order to achieve great success. Leaders accomplish this by listening to others and being sensitive to their needs. They must find the common thread that ties members of the organization together and appeal to it in order to gain commitment. 


\section{Challenge the Process}

Good leaders understand that "certainty and routine breed complacency" (p. 176). No one can achieve their personal best by keeping things the same. Leaders look forward to challenges and are not afraid to make mistakes.

Commitment five: search for opportunities. Good leaders make things happen by being proactive; proactive people work harder. Leaders are willing to receive ideas from anyone within or outside the organization, and they look to create meaningful challenges for others. Effective leaders look to innovate, and they seek to eliminate all non-essential routines from the organization because routine stifles creativity. Good leaders always question the status quo.

Commitment six: experiment and take risks. Effective leaders have a tolerance for error, as it is the means for learning from mistakes. They must avoid trying to devise the perfect plan. It is more important to take small steps forward than it is to remain static while trying to hammer out every detail of a plan. Leaders must make it safe for

others to take risks, and they create ownership and commitment by giving people choices.

\section{Enable Others to Act}

Good leaders understand that successful organizations are a team effort. They know they can't do it alone. Kouzes and Posner report that no personal best leadership cases promoted competition among group members. The highest levels of performance were reported when a spirit of teamwork and collaboration were evident.

Commitment seven: foster collaboration. Trust is the main ingredient in collaboration. Without trust the leader cannot lead. Additionally, the more trusted people feel the more innovative they become. It is the role of the leader to place trust in 
others in order to gain their trust. This allows the leader to create a sense of positive interdependence. Finally, the leader must reward joint effort to foster collaboration.

Commitment eight: strengthen others. Good leaders strengthen others by sharing leadership. They realize that the more power they give away, the more powerful they become. Shared power increases job satisfaction and performance. Effective leaders also provide choice in order to gain commitment, and they allow for flexibility because they understand that only the adaptive organizations will thrive. Good leaders also foster a sense of accountability. The sense of accountability breeds a feeling of empowerment.

\section{Encourage the Heart}

Leaders recognize individual as well as group contributions, and they celebrate victories and values. This allows them to stimulate individuals to perform at their best. Kouzes and Posner report that "most people rate 'having a caring boss' even higher than they value money or fringe benefits (p. 317).

Commitment nine: recognize contributions. To recognize contributions, the leader must first set clear standards. Standards allow people to concentrate, and they provide a framework from which to receive feedback. Successful leaders also have high expectations, and understand that high expectations often lead to high performance. Further, good leaders pay attention to their employees. They give the impression that they care about the employees work and don't make them feel as though they are checking up on them. The successful leader also personalizes rewards and makes rewards public. To personalize rewards, the leader must get to know the employees.

Commitment ten: celebrate the values and victories. Leaders hold public celebratory ceremonies as a reminder of the shared purpose, values, and vision of the 
organization. These gatherings promote togetherness and unity, and are a vehicle for social support. They create role models within the organization, and are a chance to renew commitment. It is also another opportunity for the leader to visibly set the example for what the organization is all about.

The Kouzes and Posner model provides a comprehensive view of exemplary leadership practices. The practices (and their corresponding commitments) are applicable to leadership roles in any setting. The purpose of this study is to examine the leadership characteristics of principals in Ohio Schools of Promise (which are subsets of HP/HP schools) through the lens of the Kouzes and Posner Leadership Profile Inventory.

\section{Summary}

This chapter demonstrates that high performing, high poverty schools do exist. Leadership is a critical component in such schools. Administrators with background knowledge of general leadership theory can apply this knowledge frequently. An understanding of Maslow's Need Hierarchy Theory, for example, compels administrators to identify students eligible for free breakfast and lunch programs as a means to increase achievement. Likewise, the principal with a solid underpinning of educational leadership theory recognizes the importance of both formal and informal induction programs for teachers new to the building. School leaders can also look to the body of research conducted on HP/HP schools to find strategies helpful in closing the achievement gap. For instance, familiarity of the correlates of effective schools gives principals a scaffold upon which to transform a high poverty school from low performing to high performing.

Awareness of the Kouzes and Posner model of leadership also has practical relevance for school administrators. Leaders can model the way by participating in the 
same professional development activities that they ask of their staff. They inspire a shared vision by collaborating with teachers to develop a building improvement plan. Principals can challenge the process by taking teams of teachers to visit other buildings which are successfully dealing with a common problem in search for a solution. Further still, the school leader can enable others to act by aligning staff into teams and giving them the responsibility to tackle a significant challenge such as a weakness in extended response answers on a state standardized test. Finally, the building leader can encourage the heart by holding celebratory staff luncheons to recognize outstanding effort by a teacher or group of teachers. The approaches highlighted from leadership theory, educational leadership, HP/HP research, and the Kouzes and Posner model can all be useful to a principal attempting to transform a school into a high performing organization. 


\section{CHAPTER 3}

Method

The purpose of this study is to examine and compare the leadership practices of urban and rural school principals that work in schools which the Ohio Department of Education has identified as high performing and high poverty. Further, this study identified the best practices of these principals. The study sought to examine leadership using two methods. First, it examined the relationship between LPI scores of principals in urban Schools of Promise versus rural Schools of Promise. Secondly, this study identified best practices of principals. This was done by determining the five highest overall LPI scores of both urban and rural principals. Then, teachers from these buildings were interviewed to determine the specific actions the principals performed that may have resulted in such high leadership scores.

A protocol was established for the interview process. The protocol for interviewing teachers is broken down into three major steps: pre-interview, interview, and post-interview. This design is established to produce continuity throughout the interview process, and the structure is meant to help make all interview sessions operate smoothly. Fifteen teachers from rural schools and fifteen teachers from urban schools will be interviewed, for a total of thirty interviews.

In the pre-interview phase the participants are contacted via email to confirm the interview date and time. Next, the goals of the study are explained. Participants are reminded that their participation is voluntary, and that they need not answer all questions. The participants are then given notice that the interview will be recorded. Then the participants are assured of confidentiality and anonymity, and they are informed that the 
research study will eventually be available through electronic theses and dissertations at West Virginia University.

Upon completion of the pre-interview process the interview begins. The audio recording is activated, and the questioning process begins. Prior to each question, a short explanation of the leadership category being addressed is provided. The interview questions are:

Question 1: To model the way, leaders must do what they say and lead by example. Their deeds must be consistent with their words. In what ways does your principal demonstrate "modeling the way"?

Question 2: To inspire a shared vision, leaders must create and communicate a common vision to achieve organizational success. In what ways does your principal "inspiring a shared vision"?

Question 3: To challenge the process, leaders are proactive, innovative, and make it safe for others to experiment and take risks. In what ways does your principal "challenge the process"?

Question 4: To enable others to act, leaders must foster collaboration and share leadership. In what ways does your principal "enable others to act"?

Question 5: To encourage the heart, leaders must recognize individual and group contributions, and they celebrate successes. In what ways does your principal "encourage the heart"?

If the interviewees request greater explanation of any of the five leadership categories the researcher will provide an explanation. 
The final phase of the process is the post-interview. Participants are explained what will be done with the interview data. They are reassured of confidentiality of anonymity, and they are reminded of their ability to access the final document through West Virginia University. As a concluding comment, the participants are thanked for their cooperation.

The remainder of this chapter is divided into five sections. The first section is a description of the population and construction of the sample. The second section is a detailed look at the survey instrument. The next section discusses the design of the survey. The data collection and analysis process will conclude the chapter.

\section{Population and Sample}

The population for this study consisted of principals in Ohio Schools of Promise. The population is narrowed to include principals in buildings which had earned the distinction for at least two consecutive years. The sample is filtered additionally by limiting the survey to principals working in buildings in areas classified as rural or urban by the Ohio Department of Education. All schools were categorized as high poverty or very high poverty by ODE as well.

The Senior Evaluator for the Schools of Promise program at the Ohio Department of Education was contacted to assist in identifying the population. The ODE website for the list of Schools of Promise winners for the 2007-2008 academic years was used as a resource. The document also included the number of years each school had been awarded the distinction. The Senior Evaluator also provided a listing of all 611 school districts in the state and their economic classification. From this information, schools were identified to be included in the population. 
Several criteria must be met to be considered a School of Promise. First, at least 40 percent of the student population must be considered to be economically disadvantaged. The school must have met Adequate Yearly Progress (AYP), and, if the school is a high school, must have met the minimum graduation rate of 80 percent. In addition, at least 75 percent of all students in each grade level in the building must have passed the reading or math portion of the Ohio Achievement Test (OAT) or the Ohio Graduation Test (OGT). The OAT is administered in grades three through eight; the OGT is initially administered in the tenth grade. Further, at least 75 percent of the students fitting the low income criteria must have passed the OAT or the OGT in reading or math when combined across grade levels for the particular building. The final way for low income buildings to qualify is for 65 percent of the low income students to pass both the reading and math tests in each of the tested grades for that building.

Twenty six rural, high poverty schools earned the Schools of Promise distinction for at least a second consecutive year following the 2007-2008 academic year. Thirty eight urban or major urban schools met that same criterion during the same time frame as well. The principals of all sixty four of these schools were asked to participate in the study (see Table 1). They were sent a cover letter as well as a background and demographic data sheet (see Appendix B). They were also provided a self-addressed, stamped envelope for the return of the survey.

To conduct the interview process, the top five high scoring urban and rural principals were first identified. Then, three teachers were interviewed from each of the identified schools. The principals were asked to solicit volunteers to be interviewed by informing their staffs of the research study, then directing any interested participants to 
Table 1

Proposed Sample for Study

Urban Rural Total

HP/HP Schools

39

33

72 
Figure 1

\begin{tabular}{|l|c|}
\hline \multicolumn{2}{|c|}{ Number of Participating Schools by Grade Configuration } \\
\hline Elementary School & 26 \\
\hline Middle School & 6 \\
\hline High School & 4 \\
\hline
\end{tabular}


contact the researcher via email to arrange for interviews. Those interviewed were required to be teachers from core content curricular areas (reading/language arts, math, social studies, or science).

\section{Instrumentation}

The survey instrument used will be the Kouzes and Posner Leadership Profile Inventory (LPI) Self Observer form (see Appendix C). The LPI was developed following the analysis of thousands of surveys and case studies and over 500 in-depth interviews of leaders about their experiences when they were at their very best (LPI Online, 2008). Statements were developed describing leadership actions and behaviors in the five areas of leadership and cast upon the Likert scale. The resulting LPI consists of thirty statements (six from each leadership practice). The statements are placed upon a ten point Likert-type scale. The scale ranges from a low of (1) Almost never do what is described in the statement, to a maximum of (10) Almost always do what is described in the statement. Consequently, the range of scores is from 6 to 60 in each area of leadership practice. The LPI mean scores and standard deviations from the self surveys of exemplary leaders have been established by Kouzes and Posner (see Table 2).

The internal reliability of the instrument as measured by the Cronbach's Alpha is considered strong. Internal reliability refers to the consistency of the survey, suggesting that the items in an index (such as a Likert-scale) are measuring the same thing (Vogt, 1999). Cronbach's Alpha scores range from 0.0 to 1.0, with higher scores correlating to greater internal reliability. A score of 0.60 or higher indicates a reliable instrument. The LPI instrument maintains reliability at or above the .75 level in each of the five leadership categories (see Table 3). The sample size for this analysis of the Self survey, conducted 
Table 2

LPI Self-Survey Norms

\begin{tabular}{cccccc}
\hline & Model & Inspire & Challenge & Enable & Encourage \\
mean & 47.016 & 44.344 & 46.114 & 49.397 & 47.055 \\
s.d. & 7.098 & 8.792 & 7.215 & 6.418 & 8.199 \\
\hline
\end{tabular}

Note. Adapted from The Leadership Practices Inventory: Theory and Evidence Behind the Five Practices

of Exemplary Leaders by James Kouzes and Barry Posner. Available on the internet at http://media.wiley.com/assets/463/74/lc_jb_appendix.pdf 


\section{Table 3}

Internal Reliability of Leadership Profile Inventory Self Form

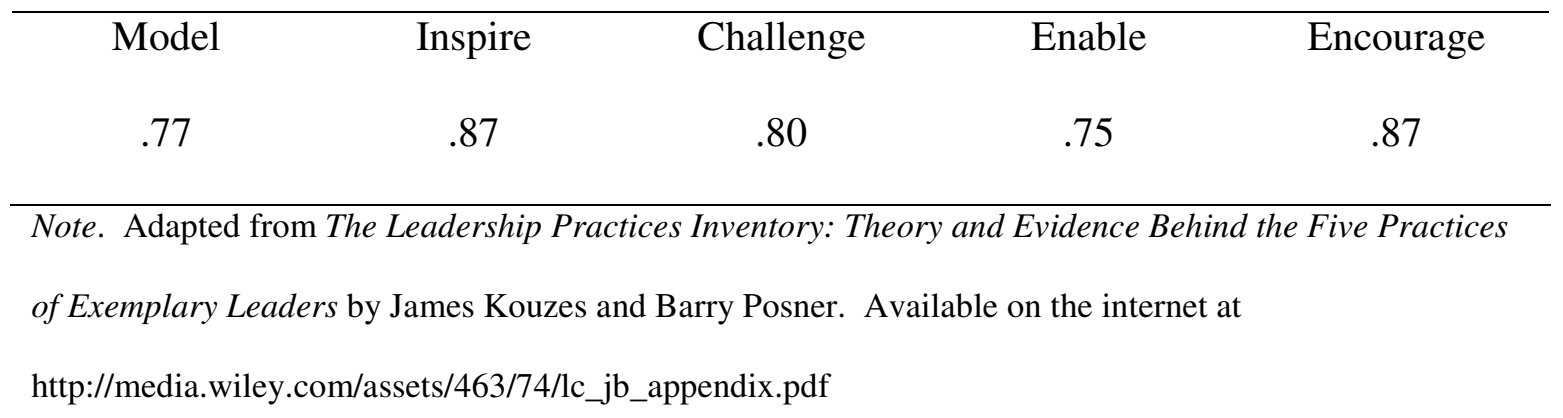


in year 2000, was 2,072. The LPI also has strong concurrent validity. This is "a way of determining the validity of a measure by seeing how well it correlates (agrees or concurs with) some other measure the researcher believes is valid" (Vogt, p. 49). Kouzes and Posner report that high leadership scores on the LPI are positively associated with factors of organizational and managerial success (Leadership Challenge, 2008).

Kouzes and Posner cite dozens of such studies in a wide variety of leadership settings. Notably, Knab (1999) conducted a study of principals in Blue Ribbon Award winning schools. The LPI scores of these principals were significantly higher than principals in schools not winning the award.

\section{Data Collection and Analysis}

The surveys were mailed to the sample, and a stamped return envelope was included. Prior to the mailing the Senior Evaluator emailed the sample population. The purpose was to alert principals to the survey which they were about to receive, and to encourage their participation. A brief demographic questionnaire was included with the survey to ensure that the current principal was also in the same job assignment during the year(s) the school achieved the Schools of Promise award. Completed surveys were returned to the researcher's home address. The five research questions affiliated with the survey and their corresponding null hypotheses are listed below. They are accompanied with the statistical method used to answer each question.

RQ1: Is there a difference in the LPI scores between principals in terms of "modeling the way" in urban and rural Ohio Schools of Promise?

Ho1: There is no difference in the LPI scores between principals in terms of "modeling the way" in urban and rural Ohio Schools of Promise? 
RQ2: Is there a difference in the LPI scores between principals in terms of "inspiring a shared vision" in urban and rural Ohio Schools of Promise?

Ho2: There is no difference in the LPI scores between principals in terms of “inspiring a shared vision" in urban and rural Ohio Schools of Promise?

RQ3: Is there a difference in the LPI scores between principals in terms of "challenging the process" in urban and rural Ohio Schools of Promise?

Ho3: There is no difference in the LPI scores between principals in terms of "challenging the process" in urban and rural Ohio Schools of Promise?

RQ4: Is there a difference in the LPI scores between principals in terms of "enabling others to act" in urban and rural Ohio Schools of Promise?

Ho4: There is no difference in the LPI scores between principals in terms of "enabling others to act" in urban and rural Ohio Schools of Promise?

RQ5: Is there a difference in the LPI scores between principals in terms of "encouraging the heart" in urban and rural Ohio Schools of Promise?

Ho5: There is no difference in the LPI scores between principals in terms of “encouraging the heart" in urban and rural Ohio Schools of Promise?

The research questions examine whether or not a difference in leadership practices exists between urban and rural principals in Ohio Schools of Promise. Five ttests were used to analyze these questions to determine if the mean LPI scores of urban and rural principals are statistically different. If a significant difference does exist, this may suggest the possibility of a different set of leadership skills necessary to develop high performing/high poverty urban schools than those skills necessary in developing high performing/high poverty rural schools. The lack of a significant difference may 
suggest the leadership skills necessary in leading either rural or urban HP/HP schools are the same or similar.

Because the research involves multiple comparisons, the risk of a familywise error exists. A familywise error refers to the probability of a Type I error occurring. This is the rejection of the null hypothesis when it is actually true (Vogt, 1999). The $p=.01$ to reduce the chance of a familywise error. This is considered to be an acceptable method for controlling this type of error.

The analysis of survey data included an overall ranking of both urban and rural principals. The five highest scoring urban and rural principals were identified. Teachers working with those principals were interviewed. The purpose of the interviews was to identify, in specific terms, the actions these principals take which they consider to be examples of exemplary leadership.

The interviews were recorded and kept on ten separate audio tapes. Two tapes were used for each leadership category. One tape was used to record data from rural principals and the other for urban principals. Each tape was labeled as such. The data was kept secure, with access available to the researcher only.

Analysis of the interview data was conducted using the constant comparative method as described by Maykut and Morehouse (1994). This approach is an inductive process for data analysis. Essentially, data are grouped and placed into categories to uncover important themes which may be targeted for further analysis or study. Four steps make up the constant comparative method, which focuses on emerging themes. The interviews were recorded and then transcribed and put into paragraph form. Once the data was collected for each subject, a coding process began to search for patterns and 
regularities in the responses. The initial broad categories were predetermined as the five leadership practices of exemplary leaders as designed by Kouzes and Posner: Model the Way, Inspire a Shared Vision, Challenge the Process, Enable Others to Act, and Encourage the Heart. The interview data was analyzed using the constant comparative method. Data was category coded according to each leadership practice. As the data analysis continued, the data was continually compared to previously categorized data. This led to a refinement of the data for greater clarity of understanding. The data was examined to search for relationships and patterns across categories. The results of the analysis are presented by leadership practice category.

The resultant information is a compilation of best practices of these school leaders. The entry level questions making up the interviews are:

Question 1: To model the way, leaders must do what they say and lead by example. Their deeds must be consistent with their words. In what ways does your principal demonstrate "modeling the way"?

Question 2: To inspire a shared vision, leaders must create and communicate a common vision to achieve organizational success. In what ways does your principal “inspire a shared vision”?

Question 3: To challenge the process, leaders are proactive, innovative, and make it safe for others to experiment and take risks. In what ways does your principal "challenge the process"?

Question 4: To enable others to act, leaders must foster collaboration and share leadership. In what ways does your principal "enable others to act"? 
Question 5: To encourage the heart, leaders must recognize individual and group contributions, and they celebrate successes. In what ways does your principal "encourage the heart"?

Guarantee of Anonymity and Confidentiality

Prior to the start of the study the researcher completed a course on social and behavioral research (Appendix D). The course consisted of eleven on-line modules, and targeted ethical standards for research in the social and behavioral fields. Topics included (but were not limited to) issues regarding risk, consent, and confidentially when conducting research with human subjects.

The anonymity of participants in all parts of the study was assured and explained in the Background and Demographic Data Sheet, which accompanied the LPI survey form. All data was secured on an external drive which was locked. The researcher was the only one to disaggregate the survey data, and was solely responsible for conducting the follow-up, open ended research questions. The confidentiality and anonymity of all participants was assured prior to the beginning of each interview.

\section{Summary}

This chapter explained all aspects of the mixed method used in this study. The quantitative piece sought to measure the leadership behaviors of both urban and rural principals in Ohio Schools of Promise. The population was further limited to schools earning the distinction at least two consecutive years. The mean scores were compared with established mean scores of exemplary leaders (using the Kouzes and Posner Leadership Profile Inventory). Also, the scores of rural principals were compared with those of urban principals. 
A qualitative piece was included as part of the study to add value to the results. The highest scoring principals in each leadership category were interviewed. The purpose of the interviews was to identify, in specific terms, the actions these principals took which led to high scores in each leadership category. An analysis of the interviews reveals insight into the best practices of principals in Ohio Schools of Promise. Table 4 presents the researchers timeline for completion of the study. 
Table 4

Timeline for Study

\begin{tabular}{|c|c|c|c|c|}
\hline 2008 & Week 1 & Week 2 & Week 3 & Week 4 \\
\hline Sept. & & $\begin{array}{l}\text { Prospectus } \\
\text { preparation }\end{array}$ & $\begin{array}{l}\text { Prospectus } \\
\text { preparation } \\
\text { secure prospectus } \\
\text { exam date }\end{array}$ & $\begin{array}{l}\text { Prospectus } \\
\text { preparation }\end{array}$ \\
\hline Oct. & $\begin{array}{l}\text { Prospectus } \\
\text { preparation }\end{array}$ & $\begin{array}{l}\text { Prospectus } \\
\text { preparation }\end{array}$ & $\begin{array}{l}\text { Defend proposal } \\
\text { Contact ODE for } \\
\text { email notice to } \\
\text { alert participants; }\end{array}$ & $\begin{array}{l}\text { Mail LPI surveys } \\
\text { to participants }\end{array}$ \\
\hline Nov. & Data collection & Data collection & Data collection & Data collection \\
\hline Dec. & Data collection & Data collection & Data collection & Data collection \\
\hline 2009 & & & & \\
\hline Jan. & Data collection & Data collection & Data analysis & Data analysis \\
\hline Feb. & Interviews & Interviews & $\begin{array}{l}\text { Interviews; } \\
\text { qualitative } \\
\text { analysis }\end{array}$ & $\begin{array}{l}\text { Qualitative } \\
\text { analysis; write }\end{array}$ \\
\hline Mar. & $\begin{array}{l}\text { Qualitative } \\
\text { analysis; write }\end{array}$ & $\begin{array}{l}\text { Meet with Dr. } \\
\text { Chapman; write } \\
\text { and revise }\end{array}$ & $\begin{array}{l}\text { Meet with Dr. } \\
\text { Chapman; write } \\
\text { and revise }\end{array}$ & $\begin{array}{l}\text { Meet with Dr. } \\
\text { Chapman; write } \\
\text { and revise }\end{array}$ \\
\hline April & $\begin{array}{l}\text { Secure date for } \\
\text { dissertation } \\
\text { defense; prepare } \\
\text { for defense }\end{array}$ & $\begin{array}{l}\text { Prepare for } \\
\text { defense }\end{array}$ & $\begin{array}{l}\text { Prepare for } \\
\text { defense; defend } \\
\text { dissertation }\end{array}$ & $\begin{array}{l}\text { Revisions to } \\
\text { dissertation; } \\
\text { Submit ETD } \\
\text { version }\end{array}$ \\
\hline May & Graduation & & & \\
\hline
\end{tabular}




\section{CHAPTER 4}

\section{RESULTS}

In this chapter, a description of the characteristics of the principals who participated in the research and their schools is rendered. The second part of this chapter will answer the research questions posed in chapter three. The third section will briefly describe the researcher, and the fourth section will describe the interview process. The next section of this chapter will present considerations of the best practices of principals in Schools of Promise by reporting the themes identified through the constant comparative analysis of teacher interviews. A brief summary will conclude the chapter. Principal and School Characteristics

A total of 64 schools fit the criteria for this study. All schools were categorized as high poverty or very high poverty by the Ohio Department of Education (ODE). The United States Department of Education considers a school's free and reduced lunch rate as the primary measure of student poverty. The schools in this study all had a free and reduced lunch rate over forty percent. The ODE categorizes schools over the forty percent free and reduced lunch rate as high poverty. The schools were also recognized as Schools of Promise, which is an award of distinction given to schools characterized by high poverty rates that perform at high levels on Ohio Achievement Tests in either reading or mathematics. The population was further narrowed to include only principals in buildings which had earned the Schools of Promise distinction for at least two consecutive years.

The principal of each school was mailed a survey and invited to participate. Of the 26 rural school principals asked to participate 19 responded (a 73\% return rate). The 
principals of 38 urban or major urban schools were targeted for the survey. Seventeen of these subjects responded (a $45 \%$ return rate). The composite return rate for all surveys was $56.25 \%$.

There were 26 elementary principals that participated, 14 were from urban schools and 12 were from rural schools (see Table 5). Four high school principals (3 rural, 1 urban) participated, and six middle school participants (4 rural, 2 urban) completed the survey (see Figure 1).. Two principals surveyed had terminal degrees; the remainder had masters level degrees.

The mean student enrollment for all schools was 363.67; the range for this group was 176 to 770 . The average experience for all principals was 12.03 , with the range being 1 to 28 . The cost per pupil expenditure mean for the entire group was $\$ 8,801.94$; the range here being $\$ 7,429$ to $\$ 12,085$. The state average per pupil was $\$ 9,622$ for the same time period. Finally, the total student teacher ratio average was one teacher for every 13.57 students, with the range being 10.7 to 20.67 .

A comparison of the LPI mean scores of principals against the norms established by Kouzes and Posner reveals several things. First, it demonstrates that both the participating rural and urban principals scored themselves higher than the LPI norms in each of the five leadership categories (see Table 6). It is important to note that the number of participants in this research is far less than the $\mathrm{N}$ used to establish the Kouzes and Posner norms $(\mathrm{N}=2072)$. This could provide some explanation of the higher mean scores. When ranking the mean scores in each category, the lowest LPI mean for both rural and urban principals is in the category inspire a shared vision. The same is also true for the Kouzes and Posner LPI norms. Likewise, the category challenging the process 


\section{Table 5}

Descriptive Data Means of Participating Schools and Principals

\begin{tabular}{lllll}
\hline $\begin{array}{l}\text { School } \\
\text { Type }\end{array}$ & $\begin{array}{l}\text { School } \\
\text { Enrollment }(\mathrm{M})\end{array}$ & $\begin{array}{l}\text { Principal } \\
\text { Experience }(\mathrm{M})\end{array}$ & $\begin{array}{l}\text { Cost } \\
\text { Per Pupil (M) }\end{array}$ & $\begin{array}{l}\text { Student- } \\
\text { Teacher Ratio }\end{array}$ \\
Rural & 363.79 & 11.63 & $\$ 8,591.53$ & 13.6737 \\
$\mathrm{~N}$ & 19 & 19 & 19 & 19 \\
Urban & 363.53 & 12.47 & $\$ 9,037.12$ & 13.4576 \\
$\mathrm{~N}$ & 17 & 17 & 17 & 17 \\
Total & 363.67 & 12.03 & $\$ 8,801.94$ & 13.5717 \\
$\mathrm{~N}$ & 36 & 36 & 36 & 36 \\
\hline
\end{tabular}


Figure 1

\begin{tabular}{|l|c|}
\hline \multicolumn{2}{|l|}{ Number of Participating Schools by Grade Configuration } \\
\hline Elementary School & 26 \\
\hline Middle School & 6 \\
\hline High School & 4 \\
\hline
\end{tabular}




\begin{tabular}{|c|c|c|c|c|c|}
\hline \multicolumn{6}{|l|}{ Table 6} \\
\hline \multicolumn{6}{|c|}{ Descriptive Statistics of Principals Self-Reported Leadership Practices and LPI Norms } \\
\hline & \multicolumn{3}{|c|}{$\underline{\text { Schools of Promise Principals }}$} & \multicolumn{2}{|c|}{$\underline{\text { LPI Norms }}$} \\
\hline & School & Mean & $\mathrm{SD}$ & Mean & SD \\
\hline \multirow[t]{2}{*}{ Model the Way } & Rural & 55.32 & 4.36 & 47.02 & 7.10 \\
\hline & Urban & 55.00 & 2.92 & & \\
\hline \multirow[t]{2}{*}{ Inspire } & Rural & 47.84 & 6.53 & 44.34 & 8.79 \\
\hline & Urban & 50.00 & 4.76 & & \\
\hline \multirow[t]{2}{*}{ Challenge } & Rural & 48.79 & 5.51 & 46.12 & 7.22 \\
\hline & Urban & 51.82 & 3.73 & & \\
\hline \multirow[t]{2}{*}{ Enable } & Rural & 54.58 & 3.55 & 49.40 & 6.42 \\
\hline & Urban & 55.41 & 2.99 & & \\
\hline \multirow[t]{2}{*}{ Encourage } & Rural & 53.79 & 4.71 & 47.06 & 8.20 \\
\hline & Urban & 53.53 & 4.86 & & \\
\hline
\end{tabular}


ranks fourth among rural and urban principals; it is also ranked fourth with respect to the LPI norms.

\section{Results Across Research Questions}

Five t-tests were used to analyze these questions to determine if the mean LPI scores of urban and rural principals are statistically different. The results show whether or not urban and rural principals in Ohio Schools of Promise view their strengths and weaknesses in each of the five leadership categories similar or statistically different. By comparing the mean scores via the t-tests, a comparison of general leadership practice can take place. The overarching question is whether or not urban and rural principals, while in drastically different demographic settings, exhibit similar leadership practices. In order to reduce the chance of a familywise (Type I) error, a .01 significance level was established.

\section{Research Question 1}

Research question one examines the self-reported LPI scores of rural and urban principals in Ohio Schools of Promise in the category of "modeling the way." Table 7 shows the results of the 2-tailed independent samples t-test; equal variances are assumed. The p-value of .039 is greater than the .01 significance level. This data suggests there is no significant difference in the way the participating urban principals viewed their leadership practices in this particular category when compared with participating rural principals.

Research Question 2

Research question two examines the self-reported LPI scores of rural and urban principals in Ohio Schools of Promise in the category of "inspiring a shared vision." 
Table 7

Multiple Independent Samples t-tests

\begin{tabular}{lccccc}
\hline $\begin{array}{l}\text { Leadership } \\
\text { Practice }\end{array}$ & Sig. & $\mathrm{t}$ & $\mathrm{df}$ & $\begin{array}{c}\text { Sig. } \\
\text { (2-tailed) }\end{array}$ & $\begin{array}{c}\text { Mean } \\
\text { Difference }\end{array}$ \\
Model & .342 & -2.144 & 34 & .039 & -2.684 \\
Inspire & 1.327 & -1.122 & 34 & .270 & -2.158 \\
Challenge & 4.071 & -1.190 & 34 & .065 & -3.034 \\
Enable & .584 & -.757 & 34 & .454 & -.833 \\
Encourage & .015 & .163 & 34 & .872 & .260 \\
\hline
\end{tabular}

Note: $\alpha$ set at .01 level; equal variances are assumed. 
Table 7 shows the results of the 2-tailed independent samples t-test; equal variances are assumed. The p-value of .270 is greater than the .01 significance level. This data suggests there is no significant difference in the way the participating urban principals viewed their leadership practices principals in this particular category when compared with participating rural principals.

\section{Research Question 3}

Research question three examines the self-reported LPI scores of rural and urban principals in Ohio Schools of Promise in the category of "challenging the process." Table 7 shows the results of the 2-tailed independent samples t-test; equal variances are assumed. The p-value of .065 is greater than the .01 significance level. This data suggests there is no significant difference in the way the participating urban principals viewed their leadership practices in this particular category when compared with participating rural principals.

\section{Research Question 4}

Research question four examines the self-reported LPI scores of rural and urban principals in Ohio Schools of Promise in the category of "enabling others to act." Table 7 shows the results of the 2-tailed independent samples t-test; equal variances are assumed. The p-value of .454 is greater than the .01 significance level. This data suggests there is no significant difference in the way the participating urban principals viewed their leadership practices in this particular category when compared with participating rural principals.

\section{Research Question 5}


Research question five examines the self-reported LPI scores of rural and urban principals in Ohio Schools of Promise in the category of "encouraging the heart." Table 7 shows the results of the 2-tailed independent samples t-test; equal variances are assumed. The p-value of .872 is greater than the .01 significance level. This data suggests there is no significant difference in the way the participating urban principals viewed their leadership practices in this particular category when compared with participating rural principals.

In addition to the t-tests, a comparison of the categorical rank-order of LPI mea scores is relevant (see Table 8). The table shows that the rural and urban principals rank ordering of three of the categories is identical; the other two categories are one ordinal number apart. In four of the five leadership categories, the overall LPI mean scores for exemplary leadership are no more than one ordinal number apart from either urban and rural principals.

A demographic data sheet was included with the LPI surveys. It was used to collect general information about the schools and their principals. The demographic variables were school enrollment, years of administrative experience, cost per pupil expenditure, and student-teacher ratio. A stepwise linear regression was performed on the LPI mean scores of the Schools of Promise principals and the four demographic variables (see Table 9). The purpose of the regression analysis was to identify demographic variables that have a relationship with principal LPI scores. There is a statistically significant relationship between the composite LPI mean score of principals and both administrative years of experience and student teacher ratio at the .05 


\begin{tabular}{lccc}
\hline $\begin{array}{l}\text { Table } 8 \\
\text { Categorical Rank- } \text { Order of }\end{array}$ & \multicolumn{3}{l}{ LPI Mean Scores } \\
Category & Rural & Urban & LPI \\
Model & 1 & 2 & 3 \\
Inspire & 5 & 5 & 5 \\
Challenge & 4 & 4 & 4 \\
Enable & 2 & 1 & 1 \\
Encourage & 3 & 3 & 2 \\
\hline
\end{tabular}




\begin{tabular}{lccc}
\hline Table 9 & & \\
Summary of Regression Analysis for & Variables & Predicting & LPI Mean Score \\
\hline Variable & B & SE B & $\beta$ \\
Step 1 & & & \\
LPI Mean Score & 52.609 & 4.098 & .013 \\
Step 2 & .000 & .003 & $.399 *$ \\
Enrollment & .192 & .070 & .221 \\
Experience & .001 & .000 & $-.408 *$ \\
Cost Per Pupil & -.577 & .215 & \\
Ratio & & & \\
\end{tabular}

$*=$ statistical significance at the .05 level $(P<.05)$ 
significance level. No statistical relationship exists between LPI mean scores and school enrollment or cost per pupil expenditure.

The analysis indicates that years of administrative experience is a significant predictor of LPI mean scores $(\beta=.399, p=.010)$ among Schools of Promise principals. The administrative experience relationship is positive, suggesting that the greater number of years experience would be associated with higher LPI mean scores. The regression coefficient (B) predicts that for each increase of .192 years of experience per principal there will be an increase of one unit on the LPI survey.

The analysis indicates that student-teacher ratio is a significant predictor of LPI mean scores $(\beta=.399, p=.010)$ among Schools of Promise principals. The student teacher ratio variable has a significant inverse relationship; suggesting that lower student teacher ratios are a predictor of higher LPI mean scores $(\beta=-.408, p=.012)$. The regression coefficient (B) predicts that for each decrease of .577 in the student-teacher ratio there will be an increase of one unit on the LPI survey.

The Researcher

The researcher for this study has seventeen years experience in the field of education; twelve of which are at the administrative level. During this time the researcher has worked in five different schools. Four of these schools are in areas of high poverty as determined by their free and reduced lunch rate. The schools are all considered to be at the secondary level.

With experience as both a teacher and administrator in high poverty schools, the researcher is able to view leadership through both of these lenses. The researcher has first hand experience dealing with the pressures of accountability, and the special 
challenges pertinent to educating children from impoverished backgrounds. These experiences of the researcher may create an inherent bias, but also allow for a richer understanding of the leadership practices of principals in schools characterized by high poverty.

\section{The Interview Process}

A total of thirty teachers were interviewed; fifteen each from urban and rural schools. The principals of the selected schools were asked to provide email addresses of teachers who would consider being interviewed. The only stipulation was that the teachers had to be working in a core curricular area (reading, language arts, science, social studies, or math). The researcher used email to arrange the interviews.

All interviews were conducted via telephone. The interviews were taped, and the researcher took notes to accompany the recordings. Prior to the interviews, the participants received an explanation about the purpose of the research. Participants were informed that the interviews were being taped, and they were assured confidentiality. They were also assured that they did not have to answer any questions they did not feel comfortable answering. The participants were also informed they could stop the interview at any time. All interviews were transcribed.

Emergent Themes of the Principals' Practices Across Leadership Categories

The purpose of this study was to examine building level leadership in HP/HP urban and rural schools in Ohio. The goal of the qualitative portion of this study was to render a highly descriptive notion of the best practices of these principals. This was done by determining the five highest overall LPI scores of both urban and rural principals. Then, teachers from these buildings were interviewed to determine the specific actions 
the principals performed that may have resulted in such high leadership scores. The initial broad categories were predetermined as the five leadership practices of exemplary leaders as designed by Kouzes and Posner: Model the Way, Inspire a Shared Vision, Challenge the Process, Enable Others to Act, and Encourage the Heart. The interview data was analyzed using the constant comparative method. Data was category coded according to each leadership practice. As the data analysis continued, the data was continually compared to previously categorized data. This led to a refinement of the data for greater clarity of understanding. The data was examined to search for relationships and patterns across categories. The results of the analysis are presented by leadership practice category. The resultant information is a compilation of best practices of Schools of Promise leaders.

Model the Way

More themes emerged within the category of modeling the way than any other category. A summary of the themes, their frequencies of occurrence by interviewees, and an indication of whether or not the themes are prevalent in literature leadership are listed in Figure 1. Respondents indicated the most significant way their principal modeled the way was through their communication skills and overall accessibility. One teacher noted, "She communicates a lot and has great rapport with staff and students" (T-12). Another teacher noted, "She has a hands-on approach. She has a lot of interaction with the students" (T-24). One teacher reported the principal's strength in modeling the way was that "He's a great communicator and you always feel like you know what's going on in the building" (T-3). Other teachers underscored the importance of their accessibility to 
Figure 2

\begin{tabular}{|l|c|c|}
\hline \multicolumn{2}{|c|}{ Modeling the Way } \\
\hline $\begin{array}{l}\text { Supported } \\
\text { in Literature } \\
\text { accessible. }\end{array}$ & $\begin{array}{l}\text { Frequency of Occurrence } \\
\text { in Teacher Interviews }\end{array}$ \\
\hline $\begin{array}{l}\text { 1. The principal communicates well/is } \\
\text { 2. The principal is visible. }\end{array}$ & $x$ & 23 \\
\hline $\begin{array}{l}\text { 3. The principal appears professional. } \\
\text { 4. The principal works with teachers; } \\
\text { performs functions which teachers perform. }\end{array}$ & $x$ & 18 \\
\hline \begin{tabular}{l} 
5. The principal has a positive attitude. \\
\hline
\end{tabular} & $x$ & 16 \\
\hline
\end{tabular}


the principal. "He is very accessible. You can walk right into his office" (T-17). Another teacher remarked, "She is always available. She has an open door policy" (T26). The teachers valued the ease and level of communication they had with their principal, and appreciated the ability to address the building leader as needed.

The second most prevalent theme in this category was visibility. According to one teacher "she is visible and you always see her in the halls or on duties" (T-3). Another noted that "she greets kids every morning and knows them by name" (T-4). Still another teacher plainly explained "She doesn't hide in the office" (T-24). It became clear to the researcher that the teachers were inspired by the visibility of their principal, and that they believed it was an important part of the principal's job.

Another theme emerged regarding the professionalism of the principal. While the definition of professionalism surely may vary from teacher to teacher, it was evident that teachers believe the notion of professionalism was an important characteristic of their principal. Comments on professionalism were directed towards appearance and overall demeanor. "He always dresses and looks professional" (T-1). "She acts professional and takes care of things that need to be taken care of right away" (T-24). Several interviewees simply state that the principal "was very professional". These teachers believed the general appearance and demeanor of the principal played a significant role in how they modeled the way.

A fourth theme merged pertaining to the principals' willingness to work with teachers and perform the same tasks as teachers. "She does everything she asks the teachers to do," remarked one teacher (T-9). Another enthusiastically noted "He doesn't have a special place in the parking lot; he parks where everyone else does" (T-30). A 
similar comment by another teacher was "He walks the walk. He does things he expects the staff to do" (T-7). Several responses were similar to one teachers comment: "She participates in all the meetings with the teachers" (T-26). It became obvious that teachers believed their principal did not act as though they were superior, and they felt this was an important mind set for someone modeling the way.

The final theme which emerged referenced positive attitudes. Several teachers remarked about the positive attitude which the principal seemed to possess. Comments were made about the friendliness and cheerfulness of their principal. The interviewees identified a positive attitude as an important component of the building leader modeling the way.

\section{Inspire a Shared Vision}

When asked about the principal's ability to inspire a shared vision, the most prevalent theme which emerged was the principal's commitment to collaboration (see Figure 2). The respondents frequently mentioned the use of meetings and other collaborative strategies to unite the building under a common vision. "We have a school wide committee to chart the schools progress for the year. We all do the same programs" (T-7). Another teacher commented, "Grade level meetings make us feel like we are all on the same page" (T-4). The notion of grade level meetings was frequently present throughout the interviews. "We have a lot of short, grade level teacher meetings so we all know what we are doing" (T-10). While the utilization of building and grade level meetings was the most common theme, principals did other things which the teachers felt were important in creating a shared vision. 
Figure 3

\begin{tabular}{|l|c|c|}
\hline \multicolumn{2}{|c|}{ Inspire a Shared Vision } \\
\hline & $\begin{array}{l}\text { Supported } \\
\text { in Literature }\end{array}$ & $\begin{array}{l}\text { Frequency of Occurrence } \\
\text { in Teacher Interviews }\end{array}$ \\
\hline $\begin{array}{l}\text { 1 . The principal is committed to } \\
\text { collaboration. }\end{array}$ & $\mathrm{x}$ & 19 \\
\hline $\begin{array}{l}\text { 2. The principal makes daily use of a school } \\
\text { slogan. }\end{array}$ & $\mathrm{x}$ & 17 \\
\hline \begin{tabular}{l} 
3. The principal seeks out staff input. \\
\hline
\end{tabular} & $\mathrm{x}$ & 16 \\
\hline
\end{tabular}


Interviewees often cited some sort of building slogan which was a common part of the school day. One teacher mentioned that the principal "says the school slogan every day on the morning announcements, and this leads to a good vision" (T-7). Another teacher made a similar comment: "She gives the same announcement over the morning announcements every day. "Why are you here? We are here to learn" (T-26). Still another teacher mentioned that the principal recited a slogan over the intercom every morning and that "it is also on every memo, newsletter, and letter sent home. It keeps everyone on the same page" (T-28). To some, the recitation of a school slogan may seem trivial. For many of the teachers interviewed, however, it appeared to play a significant role in building a common school vision.

The notion of the building leader seeking out staff input was also cited as an emerging theme. When asked about the task of building a common school vision, one teacher commented "He gets input from the staff on what the vision should be" (T-20). Other interviewees concurred with the same opinion about seeking staff input. "She tries to build a consensus when at all possible" (T-11). Another teacher revealed that the principal "meets with every staff member individually and discusses their roles and tells them what she expects of them" (T-22). The researcher believes the teachers interviewed saw the solicitation of staff input as a key factor in constructing a common school vision.

\section{Challenge the Process}

The analysis of interview data resulted in the clear emergence of two themes in this category of leadership (see Figure 3). First, teachers explained that their principal 
Figure 4

\begin{tabular}{|l|c|c|}
\hline \multicolumn{2}{|c|}{ Challenge the Process } \\
\hline & $\begin{array}{l}\text { Supported } \\
\text { in Literature }\end{array}$ & $\begin{array}{l}\text { Frequency of Occurrence } \\
\text { in Teacher Interviews }\end{array}$ \\
\hline $\begin{array}{l}\text { 1. The principal is open to and supportive of } \\
\text { new ideas. }\end{array}$ & $\mathrm{x}$ & 19 \\
\hline $\begin{array}{l}\text { 2. The principal places great value on } \\
\text { professional development. }\end{array}$ & $\mathrm{x}$ & 16 \\
\hline
\end{tabular}


was open to (and supportive of) new ideas. One teacher reported that the principal "is willing to try new ideas. He will always listen to your ideas. If you find something you want to do, he always finds the money to pay for it, and it is okay if you foul up" (T-1). Another teacher said "she provides support for new or innovative strategies. She is very encouraging (T-26). A similar comment from another teacher explained that the principal "likes us to try new and different programs to help students increase achievement" (T-5). The interview data suggest that in these Schools of Promise, principals challenge the process by encouraging and supporting new, creative, and innovative ideas which come from the teaching staff.

The second emerging theme focused on the importance of professional development activities. This emphasis is clearly embedded in the comments of one teacher who explained "she is big into professional development. She just started a reading workshop to help us succeed with struggling readers. We are getting Smart Boards in every classroom and we are all being trained in this" (T-4). Another teacher commented, "we get a lot of information out of inservices" (T-9). A final comment describes a principal's emphasis on professional development. "She is always seeking

out inservice that will help us. She works hard to find people to bring in that will help us increase student achievement" (T-23). The interview data suggest that teachers and principals alike in Schools of Promise find great worth in professional development.

\section{Enable Others to Act}

Enabling others to act refers to the leader's promotion and support of teamwork, collaboration, and empowerment as a means to reach organizational goals. A single theme emerged in this category (see Figure 4). The principals embedded collaborative 
Figure 5

\begin{tabular}{|c|c|c|}
\hline \multicolumn{2}{|c|}{ Enable Others to Act } \\
\hline & $\begin{array}{l}\text { Supported } \\
\text { in Literature }\end{array}$ & $\begin{array}{l}\text { Frequency of Occurrence } \\
\text { in Teacher Interviews }\end{array}$ \\
\hline $\begin{array}{l}\text { 1. The principal has embedded collaborative } \\
\text { time for teachers to meet and plan. }\end{array}$ & $\mathrm{x}$ & 23 \\
\hline
\end{tabular}


time within the structure of the school. Clearly, many principals advocated the team approach as the preferred method of planning in these buildings "We have a school team and then we have grade level teams. She just promotes that we always work as a team" (T-11). Many teachers commented on the support for collaboration given by the principal. "She coordinates duties so we can have grade level meetings. Peer volunteers come in and we have a movie day for the kids so we can have grade level meetings" (T10) Another teacher commented, "We have team planning meetings within the school day. She gets subs to cover classes so we can meet during the day. We get to meet with teachers in other buildings of the district too" (T-28). Another comment demonstrated collaboration and empowerment: "We coordinate all our intervention activities and strategies with intervention specialists and the special needs teachers" (T-18). A similar comment made by another teacher was that the principal "asks the staff to give input into any changes that need to be made" (T-8). Another example of empowerment is evident in the following comment: "He doesn't use any strong-arm tactics to get you to do things. He involves a lot of people in decisions to get ownership and buy-in" (T-17). The researcher also noted the frequency in which teachers made use of the word team when talking about their buildings. "Our teams all take team names at the beginning of the year. Then she buys us all team shirts. Everyone gets one; even the kids" (T-4). "Everything is team oriented to her. She refers to our building as a team and our classrooms are called teams" (T-5). Teachers repeatedly used the word team when talking about their buildings or common planning time. Clearly, the principals used the word team as a strategy to promote collaboration amongst staff members.

\section{Encourage the Heart}


This category, along with the Modeling the Way category, generated the most responses from the interviewees. The themes which developed were under the umbrella of student recognition and teacher recognition (see Figure 5). The researcher broke down these categories to allow for a more detailed analysis of this category. Student recognition was broken down further into two categories: public recognition and tangible student rewards. Likewise, teacher recognition was divided into two categories: public praise and private praise.

The public recognition of students for achievement took several forms. In many instances, the school intercom system was used as a tool to acknowledge student success. Other methods of public recognition were prevalent as well. "We have a pajamas day or a backwards day if we meet certain goals" (T-6). Another teacher (T-26) commented:

She gives a lot of pats on the back. She points out what a good job kids have done over the intercom. She puts kids' names in the paper, and this is rewarding for the teachers as well. She also put their names in newsletters that go home to the parents. We have an honor roll breakfast and perfect attendance breakfast at the end of each nine weeks.

Most all teachers made reference to either quarterly or annual awards assemblies as a means to recognize student achievement as well. Many principals who frequently acknowledged students publically also used tangible rewards to celebrate success.

When discussing tangible rewards, the researcher is referring to anything given to students individually. The most common citations were breakfasts and luncheons. Other principals gave students gumballs, milkshakes, t-shirts, or bumper stickers. One teacher commented on how the principal involved the community in the rewards program. "We have rewards like pencils and pens, but we also have other awards. We have coupons donated from the community for things like free food or other small prizes" (T-16). 
Figure 6

\begin{tabular}{|l|c|c|}
\hline \multicolumn{2}{|c|}{ Encourage the Heart } & Supported \\
in Literature & $\begin{array}{l}\text { Frequency of Occurrence } \\
\text { in Teacher Interviews }\end{array}$ \\
\hline $\begin{array}{l}\text { 1. The principal publically recognizes } \\
\text { students for various achievements. }\end{array}$ & $\mathrm{x}$ & 25 \\
\hline $\begin{array}{l}\text { 2. The principal provides tangible rewards to } \\
\text { students for various achievements. }\end{array}$ & $\mathrm{x}$ & 19 \\
\hline $\begin{array}{l}\text { 3. The principal publically praises teachers } \\
\text { for their work. }\end{array}$ & $\mathrm{x}$ & 10 \\
\hline $\begin{array}{l}\text { 4. The principal privately praises teachers for } \\
\text { their work. }\end{array}$ & $\mathrm{x}$ & \\
\hline
\end{tabular}


While the types of rewards varied in the schools, it was obvious to the researcher that rewards programs for students was an important part of most of the school communities. Teacher rewards were rarely in the form of anything tangible. The interviewees most commonly referred to public praise given to staff members as the means of recognition used by the principal. One teacher (T-8) explained:

She gets good media coverage of our school when we receive awards or recognition from the state. She goes to school board meetings to inform them of our successes. Every month someone is recognized for something. She put a big sign up outside about us being an excellent school, too.

Another teacher (T-25) reported a similarity in how teachers and students were recognized: "Teachers are acknowledged by getting their names on the intercom, and their names are in newsletters sent home to the parents". Several teachers revealed that their principal held social gatherings for the teachers. This can be seen as both a reward and a team building event at the same time. "We have an outing at his house once a year. We also have a get together if someone moves on" (T-29). Other teachers mentioned teacher appreciation breakfasts or luncheons as public recognition and reward activities. While teachers seemed to appreciate public recognition, they also mentioned the individual praise the principal gave to staff members.

Most commonly, individual praise took the form of simple "thank yous" and handshakes. "She constantly verbalizes to us individually how well we do" (T-2). Other teachers mentioned notes of appreciation in teacher mailboxes as well as personalized emails as a form of recognition. It appeared to the researcher that most principals were as likely to give teachers recognition as they did students. 
This chapter describes characteristics of a sample of principals in Ohio Schools of Promise. Descriptive statistics about the principals and their buildings were provided. Statistical analysis was performed to determine if a significant difference existed among rural and urban principals in how they viewed their leadership characteristics. A regression analysis was conducted to determine if a significant relationship existed between the LPI scores of principals and four demographic variables (school enrollment, years of administrative experience, cost per pupil expenditure, and student-teacher ratio).

The second part of the chapter renders a highly descriptive notion of the best practices of the urban and rural principals who scored the highest on the Kouzes and Posner LPI. This was accomplished by interviewing a total of thirty teachers from ten different buildings. Emerging themes were revealed using the constant comparative method of data analysis. 


\section{CHAPTER 5}

\section{DISCUSSION}

The purpose of this study was to examine and compare the leadership practices of urban and rural principals in schools which the Ohio Department of Education has identified as high performing and high poverty. The study also sought to identify the best practices of these principals. These objectives were addressed through an analysis of demographic data, quantitative analysis of survey responses, and qualitative analysis of thirty interviews.

The first section of this chapter will provide conclusions based on the statistical procedures which examined the relationship between the principals' self-perceived leadership capabilities and several demographic variables. The second section of the chapter will answer the research questions. The subsequent section will make conclusions on the leadership of the principals in the five relevant leadership practices through examination of the emergent themes which evolved from the teacher interviews. The final section of the chapter will suggest implications.

\section{Leadership Perception and Demographic Characteristics}

The regression analysis discovered two significant relationships between the LPI scores of the principals and the demographic variables of their schools. First, the years of administrative experience of the principals had a positive relationship with self-reported LPI scores of the principals. This relationship suggests that more experienced principals rated themselves higher on the leadership survey than those with less experience. This finding is not surprising. Those with a greater number of years experience in any vocation are likely to have a higher level of confidence in their abilities. Veteran 
principals have experienced more change, and have most likely faced more challenges, than less experienced administrators. Presumably they have performed at an acceptable level which has led to their retention or advancement in the field of educational administration. Thus, the study confirms what one might already suspect: level of experience is a predictor of LPI score; greater years of experience linked to higher LPI scores.

The second significant relationship uncovered by the regression analysis is in reference to student- teacher ratio. A negative relationship exists. Lower studentteacher ratios are affiliated with higher LPI scores in this study. Several factors could explain this circumstance. A lower student- teacher ratio may positively impact student discipline and behavior. Student problems are often fewer when this ratio is low. Principals may judge their abilities in part to the tone of discipline in the school. Less discipline problems may result in a higher confidence level of the building administrator; thus, a higher rating on the LPI self-survey. Additionally, the amount of time the principal spends dealing with discipline problems may have an impact on the effort the administrator has towards instructional leadership. Less time on issues of student discipline may lead to an increase in the time the principal has for other worthwhile leadership initiatives.

Student- teacher ratio can also be linked to teacher satisfaction. Teachers prefer to have small classes. The effect of small class size may lead to higher teacher satisfaction and morale. This positive attitude of staff members may lead to an increase in the confidence level of the administrator. To sum, lower student- teacher ratios may have a positive effect on student discipline, the available time the principal has to 
collaborate and communicate with teachers, and increased teacher morale. These factors help create a positive school culture, thus resulting in an increase in a principal's view of their own efficacy. It is likely that the principals of the schools with low student-teacher ratios are cognizant of the many benefits it brings. As a result, they strive to create and maintain a low student-teacher ratio

\section{Research Questions}

The research questions compared the leadership practices of urban and rural principals in Ohio Schools of Promise. The instrument used was the Kouzes and Posner Leadership Profile Self-Inventory. The method of comparison was five independent samples t-tests. These tests compared the mean scores of the participating urban and rural and principals in five leadership categories.

In each of the five leadership categories there was a failure to reject the null hypothesis. This suggests that there is no significant difference in how the participating rural and urban principals scored themselves across all five leadership categories. The lack of differences in how urban and rural principals perceived their leadership is further emphasized when the means in each category were rank-ordered (as previously displayed in Table 7). In three of the five categories, urban and rural principals had identical ranks. The other two categories were one ordinal number apart. This information suggests that principals in urban and rural schools in this study have similar views regarding their strengths and weaknesses as building leaders. The rejection of the null hypothesis in each of the five leadership categories also demonstrates that the leadership styles and abilities in the principals of these high performing high poverty schools are similar regardless of the building's classification as urban or rural. 
The similarity in how principals viewed and rated their leadership style and ability implies several things. While appearing to be dramatically different in some demographic categories, these building leaders face many of the same challenges. The physical settings of the buildings differ significantly; the presence of racial and ethnic diversity among the student population differs greatly as well. However, it appears that the socioeconomic status of the buildings plays such a powerful role on leadership that it results in a similarity of styles and abilities. The impact of student SES on the leadership of these principals, then, seems to overshadow the obvious differences in the makeup of these urban and rural schools.

\section{Teacher Interviews}

The top five LPI scores from both the urban and rural principals were identified. Three teachers from each corresponding school were interviewed for a total of fifteen urban school teacher interviews and fifteen rural school teacher interviews. The interviews focused on the five leadership categories developed by Kouzes and Posner.

\section{Model the Way}

The interviewer found that this category produced a higher frequency of responses as well as a greater richness in responses than any other category. One possible reason is that participant enthusiasm was higher during the earliest portions of the interview. Since this was the first item to which teachers responded, perhaps they were willing to talk more and give greater detail. Conversely, one could also argue that responses should be more detailed (and participants more enthusiastic) as the interview progressed. This might be the case if the teachers felt a greater comfort level with the 
interview as it moved along. The researcher, however, believes there are other reasons the interviewees applied greater emphasis to this category.

The notion of modeling the way can quickly bring about vivid images, making them easier to recall. In explaining how a principal models the way, the interviewees are asked to describe what they have seen. Three other categories ask participants to describe how the principal inspires, challenges, and enables. Expressing how an individual accomplishes these things is more difficult. It is not surprising then that the final category encourages the heart, ranked second in frequency and richness of its responses. The question submitted for response in this category was "How does your principal celebrate individual and school successes of students and teachers". Once again, this type of question would more readily bring about richer descriptions than the previous three categories.

The results of the principal surveys and the teacher interviews demonstrate the value of modeling behavior by principals. Rural principals ranked themselves highest in this area and urban principals ranked this as their second highest category. When considering this along with the frequency and richness of teacher responses, it appears that the principals have a clear understanding of the power of leading by example. Leaders understand that whenever they are visible, they are being observed closely by staff, students, and other stakeholders. This scrutiny presents an excellent opportunity to model desired behaviors. The principals are able to demonstrate their values through their actions. They use their visibility as a tool. When principals model behavior, they are able to bring their values to life. 
Teachers lauded principals for their visibility and accessibility. They valued their ability to approach the leader with concerns, and this also seemed to result in creating organizational transparency. This type of relationship is conducive to a trusting environment. The principal's visibility gave teachers the sense that the principal was part of the building team. It also seemed to be a method for creating and maintaining high building morale. It is unlikely that the high level of visibility and accessibility are random or unplanned behaviors; rather, the principals understand the value of these actions and make a conscious effort to perform them.

The importance teachers placed on professionalism was also apparent. Positive comments were repeatedly made about the physical appearance of the principal as well as overall demeanor. Clearly, teachers had a vision of how their building leader should look and act. It is difficult to define professionalism, and the notion of professionalism is likely to vary from person to person. Nevertheless, the principals were aware of the professional appearance and demeanor that teachers would accept. They understood that an important part of modeling the way rests with how they dress and treat others.

An examination of the survey data, as well as an analysis of the interviews, suggests that modeling the way is one of the most widely understood leadership characteristics. It is also probably the easiest to perform. Principals at all levels of experience can perform tasks that model the way. They understand that their most powerful teaching tool is to lead by example. It is the fastest path to gaining credibility. The principals in this study maintained a high level of visibility and accessibility. They also maintained a professional appearance and demeanor. These are the primary strategies used by principals to model the way. It has been said that people won't believe 
the message unless they believe the messenger. As much as this is true, the principals of these high performing, high poverty schools took concrete strategies to secure the confidence of their teachers.

\section{Inspire a Shared Vision}

Teachers seemed to view this category as the principal's ability to create building unity and singleness of purpose. To this end, the most dominant emergent theme was the principal's commitment to collaboration. Teachers often cited the frequency and types of meetings they had with each other. Meetings appeared to take place on a regular basis. There were grade level meetings as well as content area meetings that were organized horizontally and vertically. The interviewees implied that the principal expected teams of teachers to meet, with the task of meeting instructional goals. This collaborative environment resulted in a shared vision among staff. Everyone seemed to understand what was expected of them, and they knew what everyone else was doing. The principals understood the importance of a common vision, and realized how a collaborative environment would help in building and sustaining the vision.

The number of responses that referenced the use of some sort of building slogan was somewhat surprising. The principals' promotion of a daily slogan, whether it be on the daily announcements, email correspondences with staff members, or newsletters sent home to parents appeared to be an effective way of creating a shared vision. Principals seemed to use this strategy as a rallying cry; an inspirational message. It was as though the slogan became part of the learning community's identity. The slogans proclaimed a building mission and created a sense of belonging in the school. They gave everyone 
something in common, thereby assisting in the creation of a common vision. Evidently, the building leaders understood the power of daily proclamations of building purpose.

In discussing the existence of a common school vision, teachers also pointed to the principals' solicitation of staff input. This seemed to be a collaborative way to pull the staff together and create a school vision. Thus, the vision was not some sort of topdown mandate. The vision was built, either knowingly or unknowingly, with the input of the staff. There was staff ownership. It is important to note that teachers commented on how the principal's actively sought input. The leaders did not sit idle, giving consideration to staff input only when approached with it. Rather, the principal requested input on a regular basis. Clearly, this was a strategy used to inspire a shared vision.

Leaders had more difficulty in this leadership category than in any other. This is illustrated in the results of the surveys. Both urban and rural principals ranked themselves lowest in this category. In addition, the lowest ranking category in the LPI norms is the same. The work of inspiring a vision is more complex and difficult than modeling the way. The notion of a shared vision is nebulous. It is something that can not be seen, rather it is a belief. The act of showing others (as in modeling the way), comes more easily than trying to inspire others. Nevertheless, the principals in this study understand that to inspire a shared vision they must be sensitive to the needs of others, and they must listen to them. In this way they create a shared vision. They frequently use slogans as a tool used to inspire the school community toward the vision. The effort put forth by the principals in this study indicates they understand the importance of inspiring a shared vision, and they are willing to take steps to create a shared vision in their buildings. 


\section{Challenge the Process}

To find out what principals did to challenge the process, teachers were asked what things principals did to motivate and inspire the staff to ensure that all students learned at high levels. Essentially, what did the principal do to encourage teachers to work at their highest level? Two emergent themes deserve recognition. First, interviewees reported that their principal's were open and supportive of new ideas. Teachers explained that the principals were willing to provide support in any form possible to allow them to implement new programs. In fact, the building leaders encouraged teachers to seek innovative strategies to enhance student achievement. This implies a high level of trust between principals and their staffs. The creation of trust between principals and teachers has a positive, spiraling effect. This type of relationship strengthens the bond of the staff in the building, and can only serve to enhance school culture. It helps create a fear free environment that permits risk taking. This atmosphere fosters professional growth and has a positive impact on teacher morale.

The second emergent theme was the high level of emphasis building leaders put on professional development. While the principals were open to and supportive of new ideas put forth by the teachers, they themselves actively sought out strategies and programs which might positively impact student learning. These actions can also be considered a form of modeling the way by the principal. Teachers and principals seemed to inspire each other in their searches for new programs directed at student learning. The emphasis on professional development suggests the principals place value on research based initiatives as a means for school improvement. 
To challenge the process, Kouzes and Posner (2002) explain that leaders must be proactive and look to innovate. They must also be willing to take risks and have tolerance for mistakes, and allow others to do the same. The principals in this study place great value on professional development programs; they encourage and support teacher efforts at new initiatives. The leaders understand that growth can not readily occur without risk taking. The principals seem to subscribe to Stephen Covey's notion of sharpening the saw, which promotes the values of the continual renewal of professional skills. They develop a culture of trust and high expectations, which are key components that provide the cornerstone for challenging the process.

\section{Enable Others to Act}

This category resulted in the narrowest types of responses. Teachers were asked about their principal's willingness to empower teachers, and their promotion of teamwork and collaboration. A single theme emerged: the embedding of collaborative time for teachers to meet and plan. Clearly, the principals made great efforts to do this. Creative approaches were used, such as using parent volunteers to free up teachers or bringing in substitutes to cover for teachers so they could attend meetings. In other instances, teacher schedules were structured so that common planning time was a daily occurrence.

Meeting time was either by academic team or by content area (either within grade levels or among grade levels). In either instance, the principals obviously understood that collaboration and empowerment were very powerful instruments used to accomplish organizational goals.

As a means to promote and sustain collaboration, principals referred to groups, classes, and the buildings themselves as teams. This was similar to the way the leaders 
used building slogans to promote a unified vision. Principals used a variety of ways to promote the team concept. Shirts were purchased, banners were raised, and classrooms were decorated. The building leaders understood the value of a team approach for both students and staff, and it was apparent they were reliant on teacher collaboration to enhance student learning.

The principals in this study subscribe to the idea of shared leadership and empowerment. By placing trust in the staff, the principals thereby gain the trust of the staff. The leaders seem to believe that the organizational goals can not be reached unless some interdependence is developed within the framework of the building. The interdependence results in a trusting environment that is also marked by a sense of personal accountability.

Encourage the Heart

This category prompted nearly as many responses as modeling the way, and the responses were equally as rich and descriptive. Encouraging the heart refers to the celebration of individual and organizational successes. Rewards and recognition clearly played an important role in Schools of Promise. Principals publicly acknowledged the achievements of students through daily announcements, school bulletin boards, and newsletters sent home to parents. School wide awards assemblies were also readily used as a means for recognition. Principals also used tangible rewards to celebrate the successes of students. Many teachers reported that their principal gave out small prizes such as gumballs, milkshakes, pencils, or t-shirts. Other rewards recognized the efforts of entire groups of students. Movie days and pajama days were two examples of 
principals acknowledging the achievements of groups of students. Clearly, the principals used rewards as a motivational tool to encourage student achievement.

A common thread within the student rewards theme was the frequency with which rewards were given. It seemed as though rewards in some form were distributed on almost a daily basis. The teacher responses suggested that rewards programs were a systemic part of the schools. Students had an opportunity to earn rewards on a regular basis. Rewards were not limited to academic achievement. Recognition was given to students for good behavior and excellent attendance as well. Students were also rewarded for simply improving grades. Through these types of rewards, the principals were able to extend praise and recognition beyond students that were high achievers. This gave an opportunity for all students to earn recognition. The principals of these Schools of Promise understood the value of celebrating student successes.

While recognition and rewards for teachers was not as prevalent as it was for students, it clearly played an important role in many of the buildings. The recognition of teachers was rarely anything tangible, and it was generally something simple like a hand shake and a "thank you" for a job well done. While the effort was seemingly little on the part of the administrator, the impact was great. Teachers appreciated the acknowledgement they received from their principals. It made them feel important and appeared to be a way to keep teacher morale high. Teacher recognition was both private and public. Principals held appreciation breakfasts and luncheons for their staffs, and they also praised teacher accomplishments in newsletters and on the school intercom. The principals seemed to understand that teacher recognition played an important role in the successes of the buildings as much as student recognition. 
The efforts of principals in this leadership category suggest they are mindful of the power of school culture, and that they know how to tend to it. Celebrations, rewards, and recognition are excellent ways to create and maintain a positive school culture. They become rituals within the buildings. Such events add to the folklore and history of the school. They become a spoken history of the culture of the building. They are symbols of the school's belief systems and traditions. The rewards systems serve as a guide, reminding the stakeholders of the purpose of the school.

\section{Summary of Best Practices}

Building leaders of the HP/HP schools in this study exhibit some common practices across the five leadership categories. Principals use the power of modeling the way as a tool to guide their schools. They maintain high visibility within the school community, and they use this to display a professional appearance and demeanor which helps them demonstrate their values. The principals are easily accessible to staff members; this helps to promote a free flow of ideas and helps to build a culture of trust and transparency within the building. The principals also readily take on tasks which teachers routinely perform, such as bus duties and other supervisory roles. Such a willingness to work alongside the teachers helps them demonstrate their values as well as a commitment to teamwork and collaboration. Modeling the way is an important device used to promote a positive school culture.

Principals inspire a shared building vision by fostering a collaborative culture within the building. They insist on teachers meeting by grade level, among grade levels, or along curricular lines as the systemic approach to addressing building challenges. The development of collaborative environments enabled principals to create a common vision 
within their buildings. This common vision is more than a statement on a bulletin board or a handbook. It assures everyone targets the same goals and strategies. Building leaders successfully used slogans and catch phrases as a unifying tool to create singleness of purpose and to promote a common vision of student expectations and success. The principals empowered teachers in developing the vision. They actively sought out staff input and clearly valued teacher insights and suggestions.

Principals in these low SES schools had to challenge their staffs in order to raise student achievement. The leaders studied in this research were open to innovative and creative ideas brought forth by the staff. They successfully built a culture of trust that is permissive of risk taking. The teachers work in a fear free environment that supports, encourages, and values innovative approaches that may enhance student achievement. To promote creativity and innovation, the principals placed great emphasis on professional development activities. The leaders understood the power of research based initiatives in helping students achieve at high levels.

The principals of the HP/HP schools in this study supported their emphasis on collaboration and teamwork by embedding collaborative time within the regular school day. They appeared to believe that teacher collaboration would be less effective if it took place outside normal school hours. The leaders viewed time as a variable; not a constant. They sought out creative ways to provide time for teachers to meet together during the school day. The principals were sensitive to the needs of teachers, and seemed to have a solid grasp of the principles of adult learning.

Principals in these schools of promise understood the value of reward and recognition, and made them an important part of the rituals and ceremonies of the 
schools. Student and teacher praise played an important role in the culture of the school. The principals used it as a way to promote the shared values and beliefs of the school community. Like modeling the way, the principals saw rewards and recognition as a visible way to promote encourage staff and student achievement. It was an important part of building and maintaining morale of staff and students alike. Rewards were both tangible and non-tangible in nature, and praise was given publically and privately. Praise and recognition were a common occurrence. The celebration of student successes was not limited to academics; students were also acknowledged for behavior and attendance. Praise and recognition also was not limited to individuals. Principals also acknowledged groups of students for a job well done. It was quite evident that the recognition of student successes and teacher efforts played an important role in the Schools of Promise.

\section{Implications for Further Research}

This research serves to add to the existing body of research on leadership; specifically leadership in high performing and high poverty schools. The principal surveys and teacher interviews provide insight into the leadership practices of principals in Ohio Schools of Promise. Modification of this study may be performed to deepen the understanding of the characteristics and practices of these principals.

To gain a more holistic view of the best practices of these principals, a replication of this study may be performed which adds interviews of the selected principals. Such a study would allow for a comparison of teacher perceptions of their principal with the principal's own reflections. This type of comparison would be of interest to principals, who certainly want their actions and attitudes to be perceived accurately. 
Another way to round out the profile of principals in Schools of Promise is to add the Kouzes and Posner LPI observer survey to the study. The observer survey is virtually identical to the self survey. This survey would add an assessment of leadership practices as perceived by the teachers. The data would yield similarities and differences in perceptions of leadership behaviors. The information could be used to identify areas of strength and weakness among principals in high performing and high poverty schools. The results could be influential for principal preparation programs. The data could also be considered when determining the professional development needs of principals.

A worthwhile study of a similar nature would be a replication of the study using a different group of demographic variables to identify the principals and schools for the population. A comparison of Schools of Promise principals with principals of schools ranked as "Excellent" (according to the Ohio Department of Education) that also have a free or reduced lunch rate under 10 percent would yield interesting results. The focus on the perceived strengths and weaknesses of each group of principals using the LPI self and observer survey forms would provide the basis for the comparison. To gain insight into the similarities and differences of these leaders, teachers working with principals in the selected schools would be interviewed (similar to the interview protocol in this study). This information would provide a comparison of best practices of principals in high performing and high poverty schools with principals in high performing and low poverty schools.

\section{Implications for Stakeholders}

Results of this research have implications for a variety of stakeholders. The research demonstrates that students from low socioeconomic backgrounds can, and do, 
perform at a level comparable to their more affluent counterparts. The results suggest that educators are unable to use low SES as an excuse for low achievement levels. Principals currently working in buildings struggling to close the achievement gap can find strategies to help with their efforts. The best practices revealed in this research are practical approaches that most any principal can apply. They can merge these strategies with their existing skill set to improve student achievement. The best practices are the blueprint for success in closing the achievement gap in Ohio Schools of Promise. Building levels unsuccessful in closing the gap may adopt these strategies in part or in their entirety with the goal of meeting the federal mandate of adequate yearly progress.

District level leaders frustrated with an inability to close the achievement gap can also gain valuable insight from this study. This research demonstrates that the achievement gap is being eliminated or dramatically reduced in many schools. It also demonstrates practical approaches which school leaders can take to move schools and districts in that direction. Leaders at the district level may consider professional development activities for their principals that target the best practices from this study across the five leadership categories. Central office administrators may also consider using the LPI self and observer survey forms as a means to collect data about current leadership practices of building level administrators. The resulting data can give direction for coordinators of professional development to design study groups, seminars, or other collaborative activities designed to improve the effectiveness of principals in enhancing student achievement.

Graduate level educators in principal preparation programs may consider the results of this research when developing course content. The five leadership categories 
and the best practices revealed within them can be used as the basis for problem based learning activities. Students may be given a variety of real-life school scenarios; then be asked to respond to them through the viewpoint of one or more of the five leadership categories while considering the best practices approaches. This approach facilitates critical thinking among students, and gives them an opportunity to apply their problem solving skills and knowledge of leadership to real-world situations. Additionally, the high stakes associated with closing the achievement gap requires new principals to be ready to immediately take action to remediate the problem. Knowledge of practical strategies which can be readily applied by new principals is useful.

\section{Conclusion}

The challenge faced by American educators of closing the achievement gap is great. However, and can (and is) being done. This study adds to the body of existing research that examines how schools are closing the achievement gap. More specifically, it focuses on what leaders in high poverty schools can do to help their students achieve at high levels. The results of this study demonstrate that there are specific strategies leaders can take to help close the gap. The study suggests important steps which can be taken by educators at the building and district levels, as well as the graduate level, to help all students achieve at high levels. 


\section{References}

Appalachia Educational Laboratory (2005). A case study of six high-performing schools in Tennessee. Charleston, WV: Edvantia.

Barth, Patte et al (1999). Dispelling the myth: High poverty schools exceeding expectations. Washington DC: Education Trust.

Barth, Roland (2002). The culture builder. Educational Leadership, 59, 6-12.

Baum, S. \& Payea, K. (2005). The benefits of higher education for individuals and society. The College Board. Retrieved January 12, 2008 from http://www.collegeboard.com/prod_downloads/press/cost04/EducationPays2004. pdf

Billig, Shelly (2005). Closing the achievement gap. Lessons from successful schools. Washington DC: United States Department of Education.

Bogdan, R. \& Biklen, S. (1998). Qualitative research for education: An introduction to theory and methods. Needham Heights, MA: Allyn \& Bacon.

Bolman, L. \& Deal, T. (1997). Reframing organizations: Artistry, choice, and leadership. San Francisco: Jossey-Bass.

Brookover, W. \& Lezotte, L. (1979). Changes in school characteristics coincident with changes in student achievement. Washington D.C.: National Institute of Education. (Eric Document Reproduction Services ED 181 005)

Burns, J. (1978). Leadership. New York: Harper \& Row.

Carter, S. (1999). No excuses: Seven principals of low-income schools who set the standard for high achievement. Washington D.C.: Heritage Foundation. (Eric Document Reproduction Services ED 437 488) 
Deal, Terrence and Peterson, Kent (1999). Shaping school culture. San Francisco: Jossey-Bass.

Dewey, J. (1916). Democracy and education. New York: The Free Press.

DuFour, R. \& Eaker, R. (1992). Creating the new American school: A principal's guide to school improvement. Bloomington, Indiana: National Educational Service.

DuFour, R. (2005). On common ground: The power of professional learning communities. Bloomington, Indiana: The National Educational Service.

DuFour, R. \& Burnette, B. (2002). Pull out negativity by its roots. Journal of Staff Development, 23, 3 .

Edmonds, R. (1979). Effective schools for the urban poor. Educational Leadership, $37,15-24$.

Elmore, R. (2000). Building a new structure for school leadership. Boston: The Albert Shanker Institute.

Friedman, T. (2005). The world is flat: A brief history of the twenty-first century. New York: Farrar, Straus, and Giroux.

Fullan, Michael (2003). Leading in a culture of change. Jossey-Bass: San Francisco. Haycock, Kati (2001). Closing the achievement gap. Educational Leadership, 58 (6), 611.

Hersey, P. and Blanchard, K. (1982). Management of organizational behavior. (Englewood Cliffs, NJ: Prentice-Hall).

Herzberg, F. (1967). The motivation to work. New York: Wiley. Hessel, Karen and Holloway, John (2002). A framework for school leaders: Linking the ISLLC standards to practice. Princeton, NJ: Educational Testing Service. 
Hirsh, Stephanie (2005). Professional development and closing the achievement gap. Theory Into Practice, 44 (1), 38-44.

Hoy, W. \& Miskel, C. (2005). Educational administration: Theory, research, and practice. New York: McGraw-Hill.

Johnson, Joseph and Asera, Rose (1999). Hope for urban education: A study of nine high-performing, high-poverty urban elementary schools. Austin, TX: Charles

\section{A. Dana Center.}

Knab, D.(1998). Comparison of the leadership practices of principals of Blue Ribbon Schools with principals of randomly selected schools. Unpublished doctoral dissertation, American University, Washington DC.

Kochanek, J. (2005). Building trust for better schools: Research based practices. Thousand Oaks, California: Corwin Press.

Kouzes, J. \& Posner, B. (2002). The leadership challenge. San Francisco: Jossey-Bass.

Kouzes, J. \& Posner, B. (2003). The five practices of exemplary leadership. San Francisco: Pfeiffer.

Krathwohl, D. (1993). Methods of educational and social science research. White Plains, N.Y.: Longman.

Lambert, Linda (2003). Leadership capacity for lasting school improvement. Alexandria, Virginia: ASCD.

Leadership Challenge (2008). Theory and evidence behind the five practices of exemplary leadership. Retrieved from the internet on March 3, 2008 from http://www.leadershipchallenge.com/WileyCDA/Section/id-131362.html 
Legler, R., Symonds, K., Diamond, J. Corrin, W., Levinson, J., Gordon, E., et al. (2004). Fostering the academic success of minority and low-income students. Naperville, Illinois: Learning Point Associates.

Leithwood, Keith; Louis, Karen; Anderson, Stephen; and Wahlstrom, Kyla (2004). How leadership influences student learning. New York: The Wallace Foundation.

Leithwood, Keith and Riehl, Carolyn (2003). What we know about successful school leadership. Philadelphia, PA: Laboratory for Student Success, Temple University.

LPI Online (2008). About LPI - The methodology. Retrieved from the internet on April 17, 2008 from https://www.lpionline.com/lpi/helpInfo/methodology.jsp

Lezotte, L. (2008). Revolutionary and evolutionary: The effective schools movement. Retrieved from the internet on February 11, 2008 from www.effectiveschools.com/downloads/Rev/Ev.pdf

Maslow, A. (1943). A theory of human motivation. Psychological Review, 50, 370-396.

McGee, G. (2003). Closing Illinois' achievement gap: Lessons learned form the "Golden Spike" high poverty high performing schools. (Eric Document Reproduction Services ED 478 485)

McGregor, J. (1960). The human side of enterprise. New York: McGraw-Hill.

Meehan, Merrill, et al (2003). Classroom environment, instructional resources, and teaching differences in high-performing Kentucky schools with achievement gaps. (Eric Document Reproduction Services No. ED 478 672)

Murnane, R. \& Levy, F. (1996). Teaching the new basic skills: Principles for educating children to thrive in a changing economy. New York: The Free Press. 
National Center for Educational Statistics (2006). Trends in the achievement gap in reading and mathematics. Retrieved from the internet on June 14, 2006 from http://nces.ed.gov/programs/coe/2006/section2/indicator14.asp

Neuman, M. \& Simmons, W. (2001). Leadership for student learning. Phi Delta Kappan, 82(1), 9-12.

North Central Regional Educational Laboratory (2004). Perspectives on the gaps. Fostering the academic success of minority and low-income students. Retrieved June 19, 2006 from http://www.ncrel.org/gap/studies/perspectives.pdf Ohio Department of Education (2003). Toward high achievement for all students. Retrieved from the Ohio Department of Education website on June 16, 2006 from http://www.ode.state.oh.us/achievement_gaps/closing_achievement_gaps_task_fo rce/AG_Task_Force_Report.pdf

Ohio Department of Education (2007). School improvement/district improvement questions and answers. Retrieved January 27, 2008 from http://www.ode.state.oh.us/GD/Templates/Pages/ODE/ODEDetail.aspx ?page=3\& TopicRelationID=129\&ContentID=2151\&Content $=52496$

Reeves, D. (2006). The learning leader. Alexandria, VA: Association for Supervision and Curriculum Development.

Shannon, G. \& Bylsma, P. (2007). Addressing the achievement gap: A challenge for Washington state educators. Olympia, Washington: Office of the Superintendent of Public Instruction.

Sherman, L. (2000). The new principal. [Electronic version]. Northwest Education Magazine, 3, 1. 
Schmoker, M. (2005). No turning back: The ironclad case for professional learning communities. In Dufour, Richard, Eaker, R., \& DuFour, Rebecca (Eds.), On common ground: The power of professional learning communities (pp. 135-153). Bloomington, Ind.: National Education Service.

Sergiovanni, Thomas (2006). The principalship: A reflective practice. Boston: Allyn \& Bacon.

Sparks, D. (2005). Leading for transformation in teaching, learning, and relationships. In Dufour, Richard, Eaker, R., \& DuFour, Rebecca (Eds.), On common ground: The power of professional learning communities (pp. 155-175). Bloomington, Ind.: National Education Service.

Taylor, F. (1947). The principles of scientific management. New York: Norton.

Teske, P. \& Schneider, M. (1999). The importance of leadership: The role of school principals. Arlington, VA: The PricewaterhouseCoopers Endowment for The Business of Government. (Eric Document Reproduction Services ED 031 955)

Togneri, W. and Anderson, S. (2003). Beyond islands of excellence: What districts can do to improve instruction and achievement in all schools. Alexandria, VA: Learning First Alliance.

United States Census Bureau (2007). Educational attainment in the United States: 2007. Retrieved from the internet on January 26, 2008 from http://www.census.gov/population/www/socdemo/education/cps2007.html Viadro, D. (2000). Minority gaps smaller in some Pentagon schools. Education Week, 19 (29), 1, 20-21. Retrieved from the internet June 19, 2006. 
Vogt, W. (1999). Dictionary of statistics and methodology. New York: Sage Publications.

Weber, G. (1971). Inner-city children can be taught to read: Four successful schools. Washington D.C.: Council For Basic Education. (Eric Document Reproduction Services ED 057 125).

Waters, J. T., Marzano, R. J., \& McNulty, B. A. (2003). Balanced leadership: What 30 years of research tells us about the effect of leadership on student achievement. Aurora, CO: Mid-continent Research for Education and Learning.

Yukl, G. (1991) Leadership in organizations. Englewood Cliffs, New Jersey: PrenticeHall. 


\title{
Appendix A
}

\section{6 - 2007 State Superintendent's Schools of Promise}

\author{
2006 - 2007 Selection Criteria \\ All public elementary and secondary schools administering Ohio Achievement and Ohio Graduation Tests were considered. Schools were selected based on the \\ following criteria: \\ 1. The school served 40 percent or more economically disadvantaged students, as reported in BMIS for the 2006-2007 school year. \\ 2. The school met Adequate Yearly Progress (AYP) for 2006-2007. \\ 3. The school met the graduation rate criterion of 80 percent for the $2005-2006$ school year. \\ 4. At least 75 percent of all students in each of the tested aradelevels $(3,4,5,6,7,8$, and 10) passed the 2006-2007 Ohio Achievement Tests and or Ohio \\ Graduation Tests (OGT) in reading or mathematics. At least 85 percent of eleventh-graders passed the 2006-2007 OGT in reading or mathematics. \\ 5. At least 65 percent of the students ineach of the tested arade levials $(3,4,5,6,7,8$, and 10) passed the 2005-2006 Ohio Achievement Tests and/or Ohio \\ Graduation Tests in reading or mathematics. \\ Racial and Ethnic Subgroup Performance ${ }^{2}$ \\ 6. At least 75 percent of the students in each of the major racial and ethnic groups passed the 2006-2007 Ohio Achievement Tests and/or Ohio Graduation \\ Tests (OGT) in reading or mathematics, when combined across grade levels from third to tenth grade. At least 85 percent of eleventh-grade students in \\ each of the major racial and ethnic groups passed the OGT in reading or mathematics. \\ a. At least 65 percent of the students in each of the major racial and ethnic groups in each of the tested grades $(3,4,5,6,7$, and 8$)$ passed the 2006 - \\ 2007 Ohio Achievement Tests in reading or mathematics. \\ b. At least 75 percent of students in each of the major racial and ethnic groups in tenth-grade passed the Ohio Graduation Tests in reading or \\ mathematics. \\ c. At least 85 percent of students in each of the major racial and ethnic groups in eleventh-grade passed the Ohio Graduation Tests in reading or \\ mathematics. \\ Low-income Subgroup Performance \\ 7. At least 75 percent of the students who met the low-income criteria passed the 2006-2007 Ohio Achievement Tests and/or Ohio Graduation Tests (OGT) \\ in reading or mathematics, when combined across arade levels from third to tenth rande. At least 85 percent of eleventh-grade students who met the low- \\ income criteria passed the OGT in reading or mathematics. \\ a. At least 65 percent of the students who met the low-income criteria ineach of the tested arades $(3,4,5,6,7$, and 8) passed the 2006-2007 Ohio \\ Achievement Tests in reading or mathematics. \\ b. At least 75 percent of students who met the low-income criteria in tenth-grade passed the Ohio Graduation Tests in reading or mathematics. \\ c. At least 85 percent of students who met the low-income criteria in eleventh-grade passed the Ohio Graduation Tests in reading or mathematics.
}

\footnotetext{
${ }^{1}$ The graduation rate only applies to schools where there were at least five students who were supposed to graduate in 2005-2006.

${ }^{2}$ When evaluating test results, only racial and ethnic groups with five or more test takers were considered.

${ }^{3}$ When evaluating test results, only grade levels with five or more test takers who met the low-income criteria were considered.
} 


\section{Appendix B}

\section{Background and Demographic Data Sheet Principals in Ohio Schools of Promise}

\section{Dear Principal:}

I am currently a doctoral student at West Virginia University in the field of Educational Leadership Studies. I am also the principal of a junior high school in Ohio recently identified as a School of Promise. The purpose of my dissertation is to study the relationship between leadership and student achievement in Ohio Schools of Promise, and also to identify any differences in the leadership styles of urban versus rural principals in these schools.

The enclosed survey is titled the Leadership Profile Inventory (LPI) and was developed by James Kouzes and Barry Posner. The LPI attempts to measure five characteristics believed to exist in exemplary leaders. The LPI is considered to have strong validity, and was developed after case study analysis of over 1000 leaders considered to be exemplary. The LPI has been reprinted with the permission of Kouzes and Posner for the purposes of this study.

The survey should only take about 10 minutes to complete. Your participation is voluntary, and you do not have to respond to every survey item. Neither your name nor your school will be identified in any way when reporting the studies results in this dissertation. All your responses will remain confidential. Seventy two principals statewide are being asked to complete this survey. After the data has been collected, teachers in ten schools will be contacted for a brief phone interview. Again, participants are assured anonymity. Neither names of participants nor names of any schools will be disclosed in the dissertation.

Please complete this brief demographic data sheet and return it with the survey in the enclosed envelope. I thank you in advance for your cooperation.

Sincerely, 


\section{Appendix B}

\section{Background and Demographic Data Sheet Principals in Ohio Schools of Promise}

Please print the information listed below:

\section{(Name)}

E-Mail Address:

1. Type of school:

Elementary

Middle

High School

2. Current enrollment:

3. Years of administrative experience (including present year):

4. Highest degree attained: Masters Doctorate

5. Area of Highest Degree (e.g. Curriculum; Supervision; etc):

6. Cost per pupil:

7. Student/Teacher Ratio:

\section{(School Name)}




\section{Appendix C}

\section{Leadership Practices Inventory (James M. Kouzes and Barry Z. Posner)}

To what extent do you typically engage in the following behaviors? For each of the following statements, please circle the response that best describes how often you as a principal engage in the practice.

$\begin{array}{lll}1=\text { Almost Never } & 4=\text { Once in a while } & 7=\text { Fairly often } \quad 10=\text { Almost always } \\ 2=\text { Rarely } & 5=\text { Occasionally } & 8=\text { Usually } \\ 3=\text { Seldom } & 6=\text { Sometimes } & 9=\text { Very frequently }\end{array}$

\begin{tabular}{|c|c|c|c|c|c|c|c|c|c|c|c|}
\hline 1. & $\begin{array}{l}\text { I set a personal example of what I expect of } \\
\text { others. }\end{array}$ & 1 & 2 & 3 & 4 & 5 & 6 & 7 & 8 & 9 & 10 \\
\hline 2. & $\begin{array}{l}\text { I talk about future trends that will influence } \\
\text { how our work gets done. }\end{array}$ & 1 & 2 & 3 & 4 & 5 & 6 & 7 & 8 & 9 & 10 \\
\hline 3. & $\begin{array}{l}\text { I seek out challenging opportunities that test } \\
\text { my own skills and abilities. }\end{array}$ & 1 & 2 & 3 & 4 & 5 & 6 & 7 & 8 & 9 & 10 \\
\hline 4. & $\begin{array}{l}\text { I develop cooperative relationships among } \\
\text { the people I work with. }\end{array}$ & 1 & 2 & 3 & 4 & 5 & 6 & 7 & 8 & 9 & 10 \\
\hline 5. & I praise people for a job well done. & 1 & 2 & 3 & 4 & 5 & 6 & 7 & 8 & 9 & 10 \\
\hline 6. & $\begin{array}{l}\text { I spend time and energy making certain that } \\
\text { the people I work with adhere to the } \\
\text { principles and standards we have agreed on. }\end{array}$ & 1 & 2 & 3 & 4 & 5 & 6 & 7 & 8 & 9 & 10 \\
\hline 7. & $\begin{array}{l}\text { I describe a compelling image of what our } \\
\text { future could be like. }\end{array}$ & 1 & 2 & 3 & 4 & 5 & 6 & 7 & 8 & 9 & 10 \\
\hline 8. & $\begin{array}{l}\text { I challenge people to try out new and } \\
\text { innovative ways to do their work. }\end{array}$ & 1 & 2 & 3 & 4 & 5 & 6 & 7 & 8 & 9 & 10 \\
\hline 9. & I actively listen to diverse points of view. & 1 & 2 & 3 & 4 & 5 & 6 & 7 & 8 & 9 & 10 \\
\hline 10. & $\begin{array}{l}\text { I make it a point to let people know about } \\
\text { my confidence in their abilities. }\end{array}$ & 1 & 2 & 3 & 4 & 5 & 6 & 7 & 8 & 9 & 10 \\
\hline 11. & $\begin{array}{l}\text { I follow through on the promises and } \\
\text { commitments that I make. }\end{array}$ & 1 & 2 & 3 & 4 & 5 & 6 & 7 & 8 & 9 & 10 \\
\hline 12. & $\begin{array}{l}\text { I appeal to others to share an exciting dream } \\
\text { of the future. }\end{array}$ & 1 & 2 & 3 & 4 & 5 & 6 & 7 & 8 & 9 & 10 \\
\hline 13. & $\begin{array}{l}\text { I search outside the formal boundaries of my } \\
\text { organization for innovative ways to improve } \\
\text { what we do. }\end{array}$ & 1 & 2 & 3 & 4 & 5 & 6 & 7 & 8 & 9 & 10 \\
\hline 14. & I treat others with dignity and respect. & 1 & 2 & 3 & 4 & 5 & 6 & 7 & 8 & 9 & 10 \\
\hline 15. & $\begin{array}{l}\text { I make sure that people are creatively } \\
\text { rewarded for their contributions to the } \\
\text { success of our projects. }\end{array}$ & 1 & 2 & 3 & 4 & 5 & 6 & 7 & 8 & 9 & 10 \\
\hline
\end{tabular}




\begin{tabular}{|c|c|c|c|c|c|c|c|c|c|c|c|}
\hline 16. & $\begin{array}{l}\text { I ask for feedback on how my actions affect } \\
\text { other people's performance. }\end{array}$ & 1 & 2 & 3 & 4 & 5 & 6 & 7 & 8 & 9 & 10 \\
\hline 17. & $\begin{array}{l}\text { I show others how their long-term interests } \\
\text { can be realized by enlisting a common } \\
\text { vision. }\end{array}$ & 1 & 2 & 3 & 4 & 5 & 6 & 7 & 8 & 9 & 10 \\
\hline 18. & $\begin{array}{l}\text { I ask "What can we learn?" when things } \\
\text { don't go as expected. }\end{array}$ & 1 & 2 & 3 & 4 & 5 & 6 & 7 & 8 & 9 & 10 \\
\hline 19. & $\begin{array}{l}\text { I support the decisions that people make on } \\
\text { their own. }\end{array}$ & 1 & 2 & 3 & 4 & 5 & 6 & 7 & 8 & 9 & 10 \\
\hline 20. & $\begin{array}{l}\text { I publicly recognize people who exemplify } \\
\text { commitment to shared values. }\end{array}$ & 1 & 2 & 3 & 4 & 5 & 6 & 7 & 8 & 9 & 10 \\
\hline 21. & $\begin{array}{l}\text { I build consensus around a common set of } \\
\text { values for running our organization. }\end{array}$ & 1 & 2 & 3 & 4 & 5 & 6 & 7 & 8 & 9 & 10 \\
\hline 22. & $\begin{array}{l}\text { I paint the "big picture" of what we aspire to } \\
\text { accomplish. }\end{array}$ & 1 & 2 & 3 & 4 & 5 & 6 & 7 & 8 & 9 & 10 \\
\hline 23. & $\begin{array}{l}\text { I make certain that we set achievable goals, } \\
\text { make concrete plans, and establish } \\
\text { measurable milestones for the projects and } \\
\text { programs that we work on. }\end{array}$ & 1 & 2 & 3 & 4 & 5 & 6 & 7 & 8 & 9 & 10 \\
\hline 24. & $\begin{array}{l}\text { I give people a great deal of freedom and } \\
\text { choice in deciding how to do their work. }\end{array}$ & 1 & 2 & 3 & 4 & 5 & 6 & 7 & 8 & 9 & 10 \\
\hline 25. & I find ways to celebrate accomplishments. & 1 & 2 & 3 & 4 & 5 & 6 & 7 & 8 & 9 & 10 \\
\hline 26. & $\begin{array}{l}\text { I am clear about my philosophy of } \\
\text { leadership. }\end{array}$ & 1 & 2 & 3 & 4 & 5 & 6 & 7 & 8 & 9 & 10 \\
\hline 27. & $\begin{array}{l}\text { I speak with genuine conviction about the } \\
\text { higher meaning and purpose of our work. }\end{array}$ & 1 & 2 & 3 & 4 & 5 & 6 & 7 & 8 & 9 & 10 \\
\hline 28. & $\begin{array}{l}\text { I experiment and take risks, even when there } \\
\text { is a chance of failure. }\end{array}$ & 1 & 2 & 3 & 4 & 5 & 6 & 7 & 8 & 9 & 10 \\
\hline 29. & $\begin{array}{l}\text { I ensure that people grow in their jobs by } \\
\text { learning new skills and developing } \\
\text { themselves. }\end{array}$ & 1 & 2 & 3 & 4 & 5 & 6 & 7 & 8 & 9 & 10 \\
\hline 30. & $\begin{array}{l}\text { I give the members of the team lots of } \\
\text { appreciation and support for their } \\
\text { contributions. }\end{array}$ & 1 & 2 & 3 & 4 & 5 & 6 & 7 & 8 & 9 & 10 \\
\hline
\end{tabular}

Copyright $\odot 2003$ James M. Kouzes and Barry Z. Posner. All rights reserved. Used with permission. 


\section{Appendix D}

\section{CITI Collaborative Institutional Training Initiative}

Human Research Curriculum Completion Report

Printed on Wednesday, February 27, 2008

Learner: Mark Furda (username: markfurda)

Institution: West Virginia University

Contact

Email: mark.furda@omeresa.net

Information

al Research Investigators:

Stage 1. Basic Course Passed on 02/27/08 (Ref \# 1626627)

\begin{tabular}{|l|c|}
\hline Required Modules & $\begin{array}{c}\text { Date } \\
\text { Completed }\end{array}$ \\
\hline Belmont Report and CITI Course Introduction & $02 / 22 / 08$ \\
\hline History and Ethical Principles - SBR & $02 / 22 / 08$ \\
\hline Defining Research with Human Subjects - SBR & $02 / 22 / 08$ \\
\hline The Regulations and The Social and Behavioral Sciences - SBR & $02 / 22 / 08$ \\
\hline Assessing Risk in Social and Behavioral Sciences - SBR & $02 / 22 / 08$ \\
\hline Informed Consent - SBR & $02 / 22 / 08$ \\
\hline Privacy and Confidentiality - SBR & $02 / 22 / 08$ \\
\hline Research with Children - SBR & $02 / 26 / 08$ \\
\hline HIPAA and Human Subjects Research & $02 / 26 / 08$ \\
\hline Conflicts of Interest in Research Involving Human Subjects & $02 / 27 / 08$ \\
\hline West Virginia University & $02 / 27 / 08$ \\
\hline
\end{tabular}

For this Completion Report to be valid, the learner listed above must be affiliated with a CITI participating institution. Falsified information and unauthorized use of the CITI course site is unethical, and may be considered scientific misconduct by your institution.

Paul Braunschweiger Ph.D.

Professor, University of Miami

Director Office of Research Education

CITI Course Coordinator 
Appendix E

\section{KOUZES POSNER INTERNATIONAL 15419 Banyan Lane \\ Monte Sereno, California 95030 \\ FAX: (408) 354-9170}

July 10,2007

Mr. Mark Furda

608 Lovers Lane

Steubenville, Ohio 43953

\section{Dear Mark:}

Thank you for your request to use the Leadership Practices Inventory (LPI) in your dissertation. We are willing to allow you to reproduce the instrument as outlined in your letter, at no charge, with the following understandings:

(1) That the LPI is used only for research purposes and is not sold or used in conjunction with any compensated management development activities;

(2) That copyright of the LPI, or any derivation of the instrument, is retained by Kouzes Posner International, and that the following copyright statement is included on all copies of the instrument: "Copyright $\odot 2003$ James M.

Kouzes and Barry Z. Posner. All rights reserved. Used with permission."; (3) That one (1) electronic copy of your dissertation and one (1) copy of all papers, reports, articles, and the like which make use of the LPI data be sent promptly to our attention; and,

(4) That you agree to allow us to include an abstract of your study and any other published papers utilizing the LPI on our various websites.

If the terms outlined above are acceptable, would you indicate so by signing one (1) copy of this letter and returning it to us. Best wishes for every success with your research project.<smiles>CCO[AsH]1CCCN1</smiles>

Barby Z. Posner, Ph.D. Managing Partner

I understand and agree to abide by these conditions:

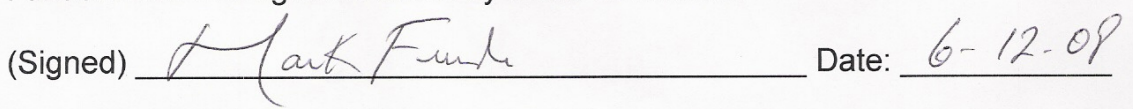

